\title{
Physiologically Based Pharmacokinetic Modeling of Bupropion and Its Metabolites in a CYP2B6 Drug-Drug-Gene Interaction Network
}

\author{
Fatima Zahra Marok, Laura Maria Fuhr, Nina Hanke (D), Dominik Selzer and Thorsten Lehr *(D)
}

check for updates

Citation: Marok, F.Z.; Fuhr, L.M.; Hanke, N.; Selzer, D.; Lehr, T.

Physiologically Based

Pharmacokinetic Modeling of

Bupropion and Its Metabolites in a

CYP2B6 Drug-Drug-Gene Interaction Network. Pharmaceutics 2021, 13, 331. https://doi.org/10.3390/pharmaceutics 13030331

Academic Editors: Marival Bermejo and Xavier Declèves

Received: 31 December 2020

Accepted: 27 February 2021

Published: 4 March 2021

Publisher's Note: MDPI stays neutral with regard to jurisdictional claims in published maps and institutional affiliations.

Copyright: (c) 2021 by the authors. Licensee MDPI, Basel, Switzerland. This article is an open access article distributed under the terms and conditions of the Creative Commons Attribution (CC BY) license (https:// creativecommons.org/licenses/by/ $4.0 /)$.
Clinical Pharmacy, Saarland University, 66123 Saarbrücken, Germany; fatima.marok@uni-saarland.de (F.Z.M.); laura.fuhr@uni-saarland.de (L.M.F.); n.hanke@mx.uni-saarland.de (N.H.); dominik.selzer@uni-saarland.de (D.S.)

* Correspondence: thorsten.lehr@mx.uni-saarland.de; Tel.: +49-681-3027-0255

Abstract: The noradrenaline and dopamine reuptake inhibitor bupropion is metabolized by CYP2B6 and recommended by the FDA as the only sensitive substrate for clinical CYP2B6 drug-drug interaction (DDI) studies. The aim of this study was to build a whole-body physiologically based pharmacokinetic (PBPK) model of bupropion including its DDI-relevant metabolites, and to qualify the model using clinical drug-gene interaction (DGI) and DDI data. The model was built in PK-Sim ${ }^{\circledR}$ applying clinical data of 67 studies. It incorporates CYP2B6-mediated hydroxylation of bupropion, metabolism via CYP2C19 and 11 $\beta-H S D$, as well as binding to pharmacological targets. The impact of CYP2B6 polymorphisms is described for normal, poor, intermediate, and rapid metabolizers, with various allele combinations of the genetic variants $C Y P 2 B 6^{*} 1, * 4, * 5$ and ${ }^{*} 6$. DDI model performance was evaluated by prediction of clinical studies with rifampicin (CYP2B6 and CYP2C19 inducer), fluvoxamine (CYP2C19 inhibitor) and voriconazole (CYP2B6 and CYP2C19 inhibitor). Model performance quantification showed 20/20 DGI ratios of hydroxybupropion to bupropion AUC ratios (DGI AUC HBup/Bup $_{\text {ratios), 12/13 DDI AUC }}$ HBup/Bup ratios, and 7/7 DDGI AUC HBup/Bup $_{\text {Bup }}$ ratios within 2-fold of observed values. The developed model is freely available in the Open Systems Pharmacology model repository.

Keywords: physiologically based pharmacokinetic modeling; bupropion; hydroxybupropion; cytochrome P450 2B6 (CYP2B6); drug-drug-interactions (DDIs); drug-gene-interactions (DGIs)

\section{Introduction}

Bupropion is used for the treatment of major depressive disorders and to support smoking cessation [1]. Nearly one out of 10 prescriptions among psychotherapeutics was attributed to bupropion in 2018 [2]. In the treatment of depressive disorders, it is either used as monotherapy or in combination with other antidepressant agents, and is administered as oral immediate release, sustained release or extended release tablets $[1,3]$.

Bupropion and various of its metabolites are pharmacologically active [4]. Hydroxybupropion is one of the major metabolites and is formed by cytochrome P450 (CYP) 2B6-mediated hydroxylation of bupropion. Bupropion and hydroxybupropion are known inhibitors of dopamine and noradrenaline reuptake transporters. Furthermore, they act as antagonists to various acetylcholine receptors and serotonin reuptake transporters [5-7]. Erythrohydrobupropion and threohydrobupropion are further metabolites of bupropion and formed via $11 \beta$-hydroxysteroid-dehydrogenase (11 $\beta$-HSD) as the rate-limiting step in the reaction pathway [8]. After administration of a single dose of $200 \mathrm{mg}$ bupropion, nearly $97 \%$ of total bupropion was recovered in urine (87\%) and feces (10\%). However, only $0.5 \%$ of unchanged bupropion was found in urine [9]. Adverse drug events or symptoms of bupropion intoxications, i.e., insomnia, vomiting, dry mouth or seizures, can be attributed to bupropion and its metabolites [10]. It was observed that erythrohydrobupropion plasma levels significantly correlate with insomnia, while threohydrobupro- 
pion is assumed to be responsible for dry mouth [11]. Moreover, hydroxybupropion induced seizures more potently than bupropion in rodent experiments [12] and immediate release administration of bupropion was associated with a higher incidence of seizures than a sustained release administration in humans $[10,13,14]$. All three metabolites are further metabolized via glucuronidation by uridine $5^{\prime}$-diphospho-glucuronosyltransferase (UGT) 2B7 [15].

According to the United States Food and Drug Administration (FDA), bupropion is listed as a sensitive substrate of CYP2B6 in clinical drug-drug interaction studies (DDIs), ref. [16] and it is subject to various CYP2B6 DDIs, when inducers or inhibitors of CYP2B6 are administered concomitantly $[17,18]$. For example, HIV patients that are on bupropion medication exhibited a $57 \%$ decrease in bupropion AUC at the initiation of antiviral therapy with ritonavir, an inducer of CYP2B6 [19,20]. Clopidogrel, an antiplatelet drug and known CYP2B6 inhibitor, was reported to decrease hydroxybupropion AUC by $60 \%$ after pretreatment with $75 \mathrm{mg}$ clopidogrel [21]. Even short-term use of CYP2B6 perpetrator drugs can seriously affect bupropion hydroxylation, as shown for the administration of fluvoxamine and voriconazole shortly before bupropion administration that caused a $90 \%$ reduction in the hydroxybupropion to bupropion $\mathrm{AUC}$ plasma ratio $\left(\mathrm{AUC}_{\mathrm{HBup} / \mathrm{Bup}}\right)$ [22]. In addition to its CYP2B6 interaction potential, bupropion is also listed as a strong clinical inhibitor of CYP2D6 [16]. However, the inhibitory effect is primarily attributed to its metabolites hydroxybupropion, erythrohydrobupropion, and threohydrobupropion [23].

In addition to its DDI potential, bupropion is also subject to CYP2B6 drug-gene interactions (DGIs). Polymorphisms in the CYP2B6 gene can result in rapid, normal, intermediate, or poor metabolizer phenotypes. Important genetic variants of CYP2B6 include CYP2B ${ }^{*} 1,{ }^{*} 4, * 5$, and ${ }^{*} 6$ with frequencies of $49 \%, 4 \%, 12 \%$, and $23 \%$ in European populations, respectively $[17,24]$. It has been shown that hydroxybupropion plasma levels and hydroxybupropion to bupropion plasma ratios are significantly altered in rapid or poor metabolizers, with $153 \%$ higher or $31 \%$ lower hydroxybupropion to bupropion AUC ratios compared to wildtype [17]. However, the clinical relevance for CYP2B6 polymorphic patients is still unclear and dose adjustment guidelines have yet to be developed.

Considering the DDI, DGI and drug-drug-gene interaction (DDGI) potential, the complex pharmacokinetics of bupropion should be thoroughly investigated. Here, physiologically based pharmacokinetic modeling (PBPK) can be a valuable tool to grasp the high level of complexity and implications of genetic polymorphisms and perpetrator drugs on the pharmacokinetics of bupropion [25]. However, a robust bupropion PBPK model connected to a strong DDGI CYP2B6 network has not been developed yet.

The aim of the presented work was the development of a PBPK model of bupropion including its three most relevant metabolites for the prediction of CYP2B6 DDI, DGI, and DDGI scenarios, and the qualification of this model using clinical data of CYP2B6 polymorphic individuals and DDI studies with different perpetrator drugs in the first published CYP2B6 DDGI network. The final model is shared with the modeling and drug development community in the Open Systems Pharmacology model repository (www.open-systems-pharmacology.org, December 2020) [26]. A transparent and comprehensive documentation of model development and evaluation is provided in the Supplementary Materials.

\section{Materials and Methods}

\subsection{Software}

The PBPK model was developed with the open-source modeling software PK-Sim ${ }^{\circledR}$ and $\mathrm{MoBi}^{\circledR}{ }^{\circledR}$ (Open Systems Pharmacology Suite 9.1, released under the GPLv2 license by the Open Systems Pharmacology community, www.open-systems-pharmacology.org (accessed on 31 December 2020)) [26]. GetData Graph Digitizer 2.26.0.20 (@ S. Fedorov) was used to digitize published clinical study data according to best practices [27]. Model input parameters were optimized by application of the Levenberg-Marquardt algorithm with multiple starting values. Local sensitivity analyses were performed within PK-Sim ${ }^{\circledR}$. 
Non-compartmental analyses, model performance measures, and plots were compiled in $\mathrm{R}$ 3.6.3 (The R Foundation for Statistical Computing, Vienna, Austria) with RStudio 1.2.5033 (RStudio PBC, Boston, MA, USA).

\subsection{Clinical Data}

Clinical studies of bupropion in single-and multiple-dose regimens were gathered and digitized from the literature [27]. The collected profiles were divided into a training $(n=19)$ and a test dataset $(n=48)$, used for model building and model evaluation, respectively [3,17-22,28-57]. Studies in the training dataset were selected to include metabolite concentration-time profiles, a wide dosing range, and different oral formulations. To minimize bias, the distribution of data on female and male populations was balanced as well. The whole dataset is documented in the clinical study tables, with their respective clinical data shown in semilogarithmic as well as linear plots in Sections 2-4 of the Supplementary Materials.

\subsection{PBPK Model Building}

Model building was started with an extensive literature search for physicochemical properties and information regarding absorption, distribution, metabolism, and excretion (ADME) processes of bupropion and its investigated metabolites.

Averaged demographic information about age, sex, ethnicity, body weight, and height listed in clinical study reports was used to create virtual individuals. If data on demographics was missing, a virtual standard individual with default values was created. Details on standard individuals are listed in Table S1.2 of the Supplementary Materials. Virtual populations of 500 individuals were created based on the demographic information provided in the clinical study reports. If no data was available, a male European population with an age distribution of 20-50 years was assumed.

Tissue distribution of enzymes and binding proteins used for the ADME processes of bupropion and its metabolites was implemented according to the PK-Sim ${ }^{\circledR}$ expression database [58]. Information on their expression is provided in Table S1.1 of the Supplementary Materials.

Tablet formulations with different bupropion release kinetics were simulated using a Weibull model (Section 1.1 in the Supplementary Materials). The Weibull shape and Weibull time parameters (50\% dissolved) were derived, if available, from dissolution profiles reported in the literature. Model parameters that either could not be sufficiently informed from the literature or were involved in important QSAR model estimates of permeability and distribution processes were optimized by fitting the model simultaneously to all plasma concentration-time profiles of the training dataset.

\subsection{PBPK Model Evaluation}

PBPK model evaluation was performed using several methods. Model predictions of plasma concentration-time profiles were graphically compared to observed profiles from the respective clinical studies. Subsequently, predicted plasma concentrations from all studies were plotted against their corresponding observed values in goodness-of-fit plots. The model performance was further evaluated by comparison of predicted to observed area under the plasma concentration-time curve (AUC) and maximum plasma concentration $\left(C_{\max }\right)$ values. AUC values (predicted as well as observed) were calculated from the time of drug administration to the time of the last concentration measurement ( $\left.\mathrm{AUC}_{\text {last }}\right)$. If measured profiles were missing, predicted AUC was calculated as reported in the corresponding study. As quantitative measures of the model performance, mean relative deviation (MRD) of all predicted and observed plasma concentrations and geometric mean fold error (GMFE) of all predicted and observed $A U C_{\text {last }}$ and $C_{\max }$ values were calculated 
according to Equations (1) and (2). Predictions with MRD and GMFE values $\leq 2$ were considered successful model predictions.

$$
\text { MRD }=10^{x} ; \quad x=\sqrt{\frac{\sum_{i=1}^{k}\left(\log _{10} \hat{c}_{i}-\log _{10} c_{i}\right)^{2}}{k}}
$$

where $c_{i}=$ the ith observed plasma concentration, $\hat{c}_{i}=$ the corresponding predicted plasma concentration, and $\mathrm{k}=$ the number of observed values.

$$
\mathrm{GMFE}=10^{\mathrm{x}} ; \quad \mathrm{x}=\frac{\sum_{\mathrm{i}=1}^{\mathrm{m}}\left|\log _{10}\left(\frac{\text { predicted PK parameter }_{\mathrm{i}}}{\text { observed PK parameter }_{\mathrm{i}}}\right)\right|}{\mathrm{m}}
$$

where predicted PK parameter ${ }_{i}=$ the ith predicted $\mathrm{AUC}_{\text {last }}$ or $\mathrm{C}_{\max }$ value, observed $\mathrm{PK}$ parameter $i_{i}=$ the corresponding observed $\mathrm{AUC}_{\text {last }}$ or $\mathrm{C}_{\max }$ value, and $m=$ the number of studies.

Local sensitivity of the AUC of bupropion, hydroxybupropion, erythrohydrobupropion, and threohydrobupropion to single parameter changes was analyzed for bupropion multiple dose administrations of the three different release formulations. Analyses included parameters that were either optimized or assumed to have an impact on AUC. A detailed description is provided in the Supplementary Materials Section 2.5.5.

\subsection{DGI, DDI and DDGI Modeling}

To model the effect of CYP2B6 genetic variants, difference in enzyme activity was expressed by variation of the Michaelis-Menten $\left(\mathrm{K}_{\mathrm{M}}\right)$ and catalytic rate constant (kcat) values for CYP2B $6^{*} 1{ }^{*} 1$ (wildtype), CYP $\left.2 B 6^{*} 1\right|^{*} 4,\left.C Y P 2 B 6^{*} 1\right|^{*} 6,\left.C Y P 2 B 6^{*} 5\right|^{*} 5$, and CYP2B $6^{*} 6{ }^{*} 6$ genotypes. Parameters that could not be informed from literature were optimized by fitting the model to clinical data based on a population with the respective genotype. If no data on genotype or phenotype of the investigated subjects was available, CYP2B6 wildtype was assumed. If mean plasma concentration-time profiles of different genotypes were reported, the most frequent one was used for model simulations.

To model the effect of DDIs, different interaction processes (competitive inhibition or induction) were incorporated into the perpetrator PBPK model with the corresponding in vitro interaction parameters values extracted from the literature. The different interaction types are described in the Supplementary Materials Section 1.6. Previously published PBPK models of the CYP2B6 perpetrator drugs rifampicin, voriconazole, and fluvoxamine were used to simulate DDI scenarios with bupropion [59-61].

To predict the rifampicin-bupropion DDGIs in carriers of different CYP2B6 alleles, inhibition and induction parameters for wildtype DDI simulations were assumed.

\subsection{DGI, DDI and DDGI Model Evaluation}

DGI, DDI, and DDGI model performance was evaluated by comparison of predicted to observed plasma concentration-time profiles of bupropion (Bup) and its CYP2B6 metabolite hydroxybupropion (HBup) after single administration and during concomitant administration of CYP2B6 perpetrator drugs (rifampicin or fluvoxamine and voriconazole). In addition, the metabolite-parent ratio $\mathrm{HBup} / \mathrm{Bup}$ of the PK parameters $\mathrm{AUC}\left(\mathrm{AUC}_{\text {last }}\right.$ or $\mathrm{AUC}_{\text {inf }}$ [AUC extrapolated to infinity]) and $C_{\max }$ was calculated for predicted and observed effect and control profiles according to Equation (3). HBup/Bup AUC and $\mathrm{C}_{\max }$ ratios were used to calculate DGI, DDI, and DDGI effect ratios according to Equation (4).

$$
\mathrm{PK}_{\text {HBup } / \text { Bup }}=\frac{\text { HBup }_{\text {PK }}}{\text { Bup }_{\text {PK }}}
$$


where Bup $\mathrm{PK}=$ PK parameter of bupropion, and HBup PK $=$ PK parameter of hydroxybupropion.

$$
\text { DGI, DDI or DDGI PK } \mathrm{HBup} / \text { Bup }=\frac{\mathrm{PK}_{\mathrm{HBup} / \text { Bup }}(\mathrm{DGI}, \mathrm{DDI} \text { or DDGI) }}{\mathrm{PK}_{\mathrm{HBup} / \text { Bup }} \text { (reference) }}
$$

where $\mathrm{PK}_{\mathrm{HBup} / \text { Bup }}=$ Hydroxybupropion-bupropion PK parameter ratio.

As a quantitative measure of DGI, DDI, and DDGI model performance, GMFE values of the predicted and observed $\mathrm{PK}_{\mathrm{Hbup} / \mathrm{Bup}}$ values as well as $\mathrm{PK}_{\mathrm{Hbup} / \mathrm{Bup}}$ effect ratios were calculated according to Equation (2).

\section{Results}

\subsection{Model Building and Evaluation}

A PBPK model for bupropion and its three metabolites, hydroxybupropion, erythrohydrobupropion, and threohydrobupropion was developed. A total of 48 clinical studies in which bupropion was administered in a wide dosing range $(20-300 \mathrm{mg})$ as immediate, sustained, and extended release tablets in single or multiple dose regimens were used in the model development process. In total, all 48 studies included plasma concentration-time profiles of bupropion, 40 of hydroxybupropion, and 17 of erythro- and threohydrobupropion. Study details are listed in Table S2.1 of the Supplementary Materials. For the extended release tablet formulation, Weibull parameters were calculated from dissolution profiles from the literature according to Langenbucher et al. [62]. For additional formulations, parameters were fitted to plasma concentration-time profiles of the training dataset. Dissolution details are listed in Table S2.2 of the Supplementary Materials.

Figure 1a illustrates the basic structure of the developed whole-body PBPK model and implemented DGI and DDI processes. Figure $1 \mathrm{~b}$ summarizes the implemented metabolism of bupropion via CYP2B6 to hydroxybupropion and via 11 $\beta$-HSD to erythro- and threohydrobupropion. Moreover, CYP2B6 metabolism is influenced by genetic variants and perpetrator drugs, such as the CYP2B6 inducer and inhibitor rifampicin $[63,64]$ and the CYP2B6 inhibitor voriconazole [65]. Bupropion metabolism via CYP2C19 was modeled to reflect minor metabolic pathways of bupropion covered by other CYPs. Since binding to therapeutic targets might influence the PK of bupropion, binding to a surrogate protein representing various neurotransmitter transporters was implemented. Furthermore, the model applied glucuronidation of the three metabolites via UGT2B7. UGT2B7 and CYP2C19 metabolism were also considered in DDI predictions, as fluvoxamine and voriconazole inhibit CYP2C19 $[65,66]$ and rifampicin induces CYP2C19. Moreover, both compounds induce and inhibit UGT2B7 [64,67]. In summary, the simulated effects include: (i) CYP2B6 polymorphisms; (ii) induction of CYP2B6, CYP2C19 and UGT2B7, and inhibition of CYP2B6 and UGT2B7 by rifampicin; and (iii) inhibition of CYP2C19 by fluvoxamine as well as inhibition of CYP2B6 and CYP2C19 by voriconazole.

Tables 1 and 2 provide an overview of the drug-dependent model parameters as well as details on the implemented metabolic processes. A description of all implemented processes and formulations with their respective model parameters is listed in the drugdependent parameter table in the Supplementary Materials. 


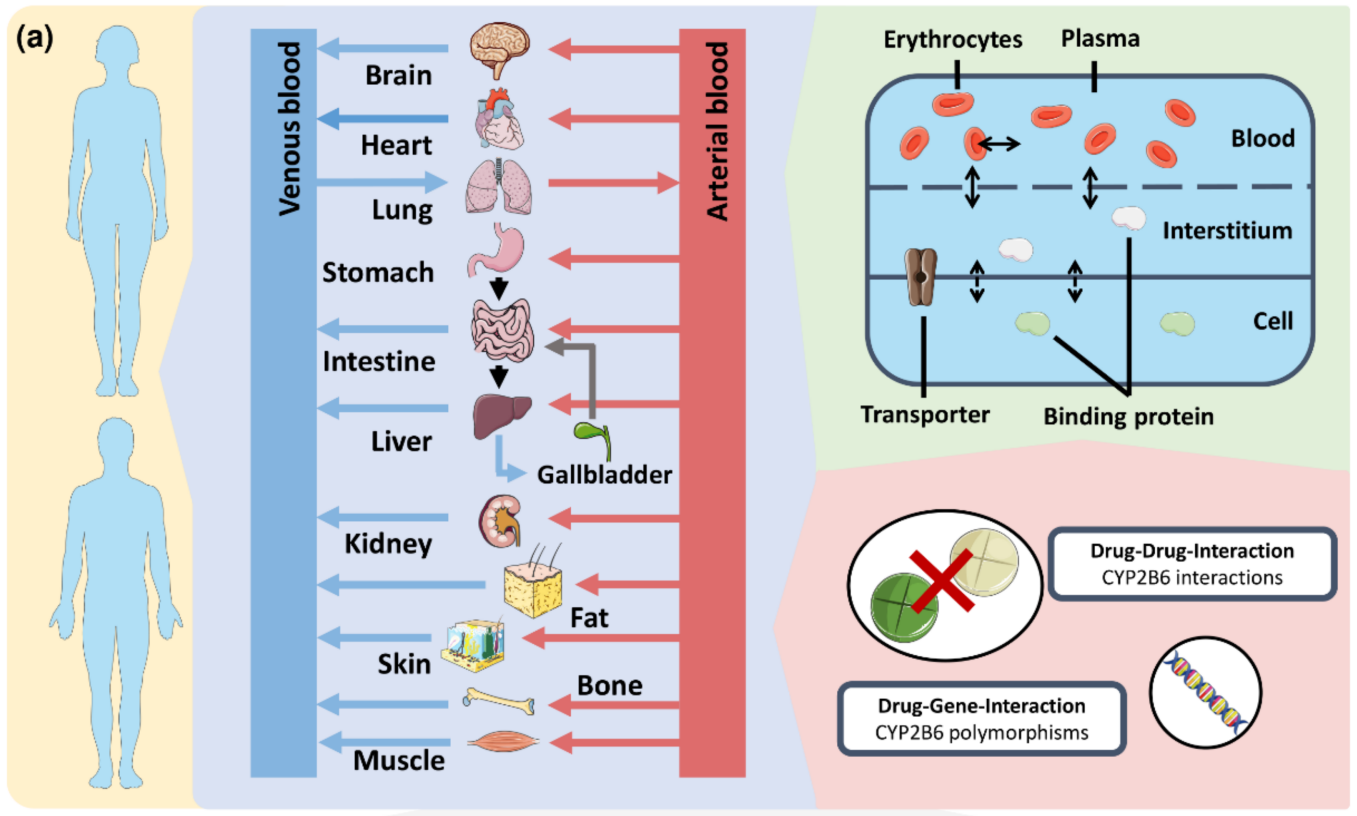

(b)

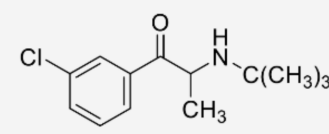

\section{Binding Partner}

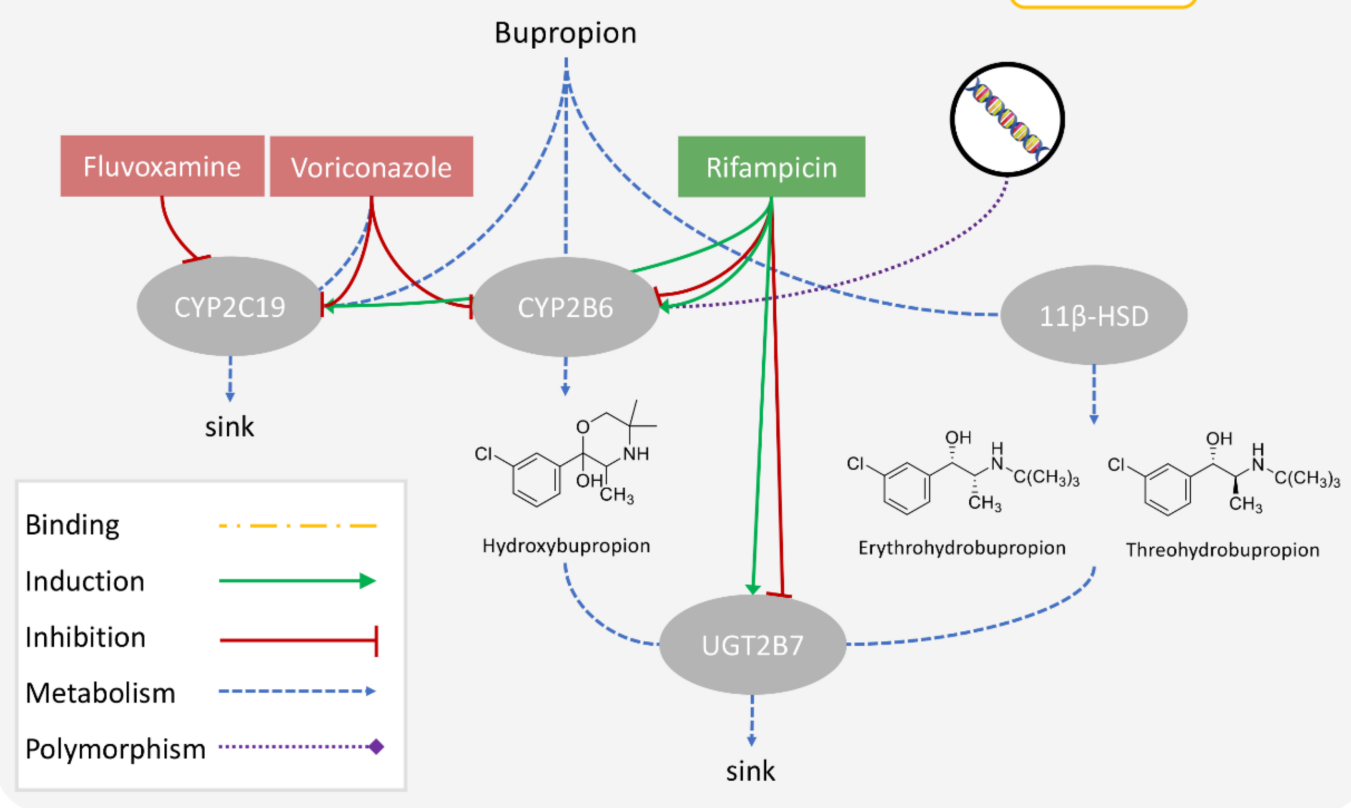

Figure 1. Modeling overview of the CYP2B6 DDGI Network. A whole-body PBPK model was augmented for the simulation of CYP2B6 drug-drug, drug-gene, and drug-drug-gene interactions (a). The model describes bupropion's metabolism via CYP2B6, CYP2C19, and 11 $\beta$-HSD (b). Its metabolites hydroxybupropion, erythro- and threohydrobupropion are transformed via UGT2B7. Binding to an unspecific binding protein, representing bupropion's pharmacological targets, was implemented. Several effects on the bupropion PK were modeled, i.e., effects of genetic polymorphisms on CYP2B6; induction of CYP2C19 by rifampicin; induction and inhibition of CYP2B6 and UGT2B7 by rifampicin; inhibition of CYP2C19 by fluvoxamine; and inhibition of CYP2B6 and CYP2C19 by voriconazole. Drawings by Servier, licensed under CC BY 3.0 [68]. 11ß-HSD: 11ß-hydroxysteroid-dehydrogenase, CYP2B6: cytochrome P450 2B6, CYP2C19: cytochrome P450 2C19, UGT2B7: uridine 5'-diphospho-glucuronosyltransferase 2 B7. 
Table 1. Drug-dependent parameters of the bupropion PBPK model.

\begin{tabular}{|c|c|c|c|c|c|c|}
\hline Parameter & Value & Unit & Source & Literature & Reference & Description \\
\hline MW & 239.74 & $\mathrm{~g} / \mathrm{mol}$ & lit. & 239.74 & [69] & Molecular Weight \\
\hline $\mathrm{pKa}$ & 8.75 & - & lit. & 8.75 & [70] & Acid dissociation constant \\
\hline Solubility $(\mathrm{pH}=7.40)$ & 365.56 & $\mathrm{mg} / \mathrm{mL}$ & lit. & 365.56 & {$[71]$} & Solubility \\
\hline $\mathrm{fu}$ & 16.00 & $\%$ & lit. & 16.00 & {$[23]$} & Fraction unbound \\
\hline Intestinal perm. & $2.76 \times 10^{-5}$ & $\mathrm{~cm} / \mathrm{min}$ & fit. & - & - & Transcellular intestinal permeability \\
\hline Partition coefficients & Diverse & - & calc. & Berez. & {$[72]$} & Cell to plasma partitioning \\
\hline Cellular Perm. & - & - & fit. & PK-Sim & {$[73]$} & Permeability into the cellular space \\
\hline EHC cont. fraction & 1.00 & - & asm. & - & & Bile fraction continuously released \\
\hline $\mathrm{K}_{\mathrm{M}} \mathrm{CYP} 2 \mathrm{~B} 6^{*} 1 \rightarrow$ HBup & $\ddagger 25.80$ & $\mu \mathrm{mol} / \mathrm{L}$ & lit. & $\ddagger 25.80$ & [74] & Michaelis-Menten constant \\
\hline $\mathrm{k}_{\text {cat }}$ CYP2B $6^{*} 1 \rightarrow$ HBup & * 10.87 & $1 / \min$ & fit. & - & - & Catalytic rate constant \\
\hline $\mathrm{K}_{\mathrm{M}} \mathrm{C} Y P 2 B 6^{*} 6 \rightarrow \mathrm{HBup}$ & $\ddagger 61.26$ & $\mu \mathrm{mol} / \mathrm{L}$ & lit. & $\ddagger 61.26$ & [74] & Michaelis-Menten constant \\
\hline $\mathrm{k}_{\text {cat }}$ CYP $2 B 6^{*} 6 \rightarrow$ HBup & $* 9.52$ & $1 / \min$ & fit. & - & - & Catalytic rate constant \\
\hline $\mathrm{K}_{\mathrm{M}} \mathrm{CYP} 2 B 6^{*} 4 \rightarrow \mathrm{HBup}$ & 12.70 & $\mu \mathrm{mol} / \mathrm{L}$ & lit. & 12.70 & [75] & Michaelis-Menten constant \\
\hline $\mathrm{k}_{\text {cat }}$ CYP2B $6^{*} 4 \rightarrow$ HBup & a 18.13 & $1 / \min$ & lit. & * 18.13 & {$[75]$} & Catalytic rate constant \\
\hline $\mathrm{K}_{\mathrm{M}} 11 \beta-\mathrm{HSD} \rightarrow$ EBup & 39.10 & $\mu \mathrm{mol} / \mathrm{L}$ & lit. & 39.10 & [76] & Michaelis-Menten constant \\
\hline $\mathrm{k}_{\text {cat }} 11 \beta-\mathrm{HSD} \rightarrow$ EBup & 2.15 & $1 / \min$ & fit. & - & - & Catalytic rate constant \\
\hline $\mathrm{k}_{\text {cat }} 11 \beta-\mathrm{HSD} \rightarrow \mathrm{TBup}$ & 8.18 & $1 / \min$ & fit. & - & - & Catalytic rate constant \\
\hline $\mathrm{K}_{\mathrm{M}}$ CYP2C19 & 8.30 & $\mu \mathrm{mol} / \mathrm{L}$ & lit. & 8.30 & [77] & Michaelis-Menten constant \\
\hline $\mathrm{k}_{\text {cat }}$ CYP2C19 & 2.59 & $1 / \min$ & fit. & - & - & Catalytic rate constant \\
\hline $\mathrm{K}_{\mathrm{D}}$ Binding partner & 0.44 & $\mu \mathrm{mol} / \mathrm{L}$ & fit. & b $0.35-0.60$ & [78-80] & Dissociation constant for binding \\
\hline $\mathrm{k}_{\text {off }}$ Binding partner & 0.05 & $1 / \min$ & fit. & - & - & Dissociation rate constant for binding \\
\hline
\end{tabular}

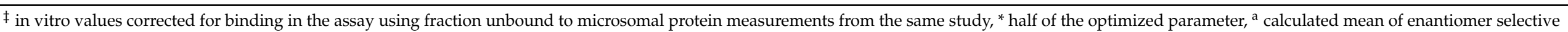

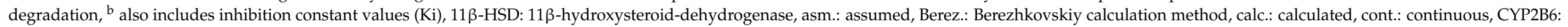

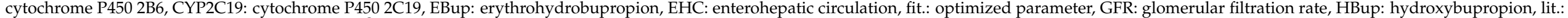
literature, perm.: permeability, PK-Sim: PK-Sim ${ }^{\circledR}$ standard calculation method, TBup: threohydrobupropion. 
Table 2. Drug-dependent parameters of the hydroxybupropion, erythrohydrobupropion and threohydrobupropion PBPK models.

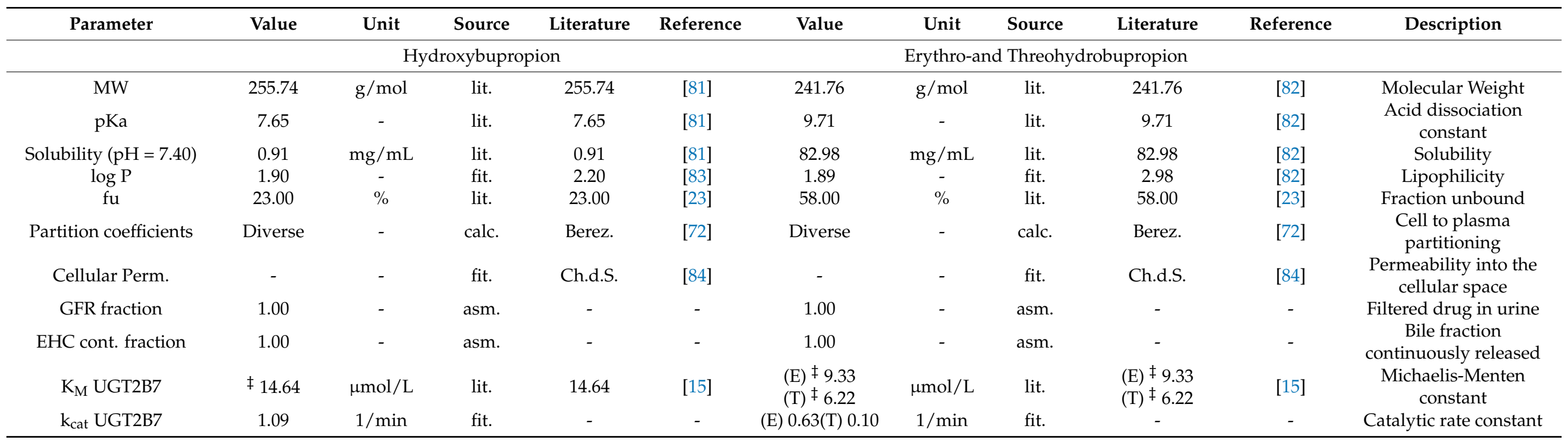

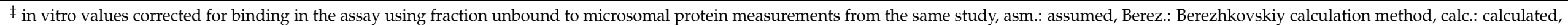

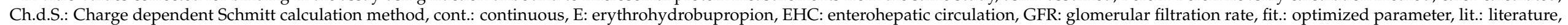
perm.: permeability, T: threohydrobupropion, UGT2B7: uridine 5'-diphospho-glucuronosyltransferase 2B7. 
Figure $2 \mathrm{a}-\mathrm{i}$ presents simulations of bupropion administration as immediate, sustained, and extended release tablets. The bupropion PBPK model accurately described and predicted plasma concentration-time profiles of bupropion and its metabolites after single and multiple dose administrations for the three different formulations. Predicted concentration-time profiles of all 48 clinical studies compared to observed data are provided on linear and semi-logarithmic scale in Figures S2.4.1-S2.4.14 in the Supplementary Materials. All simulated plasma profiles were in good agreement with their respective observed data.

(a)

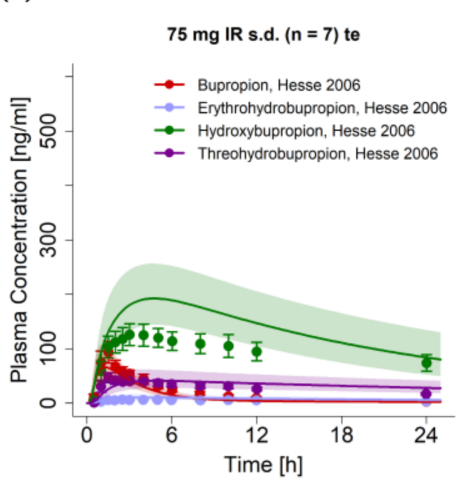

(d)

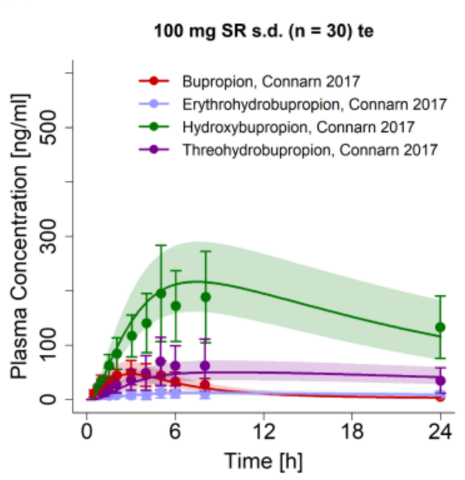

(g)

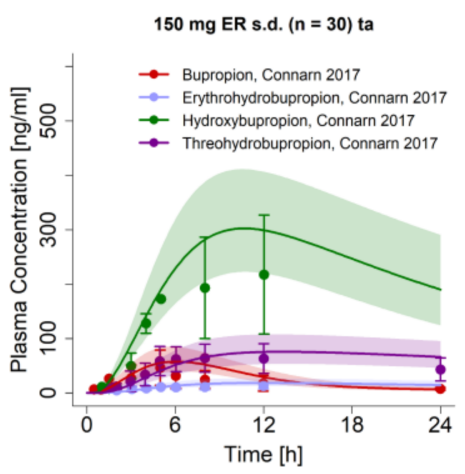

(b)

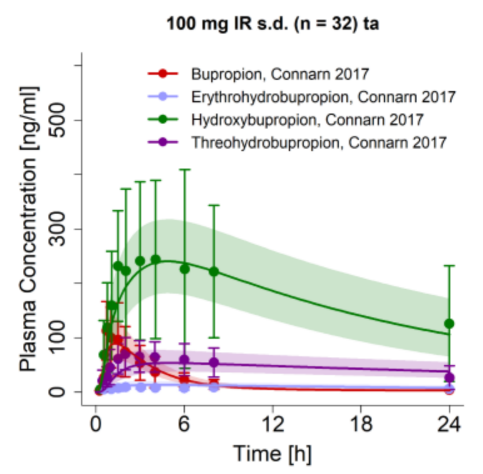

(e)

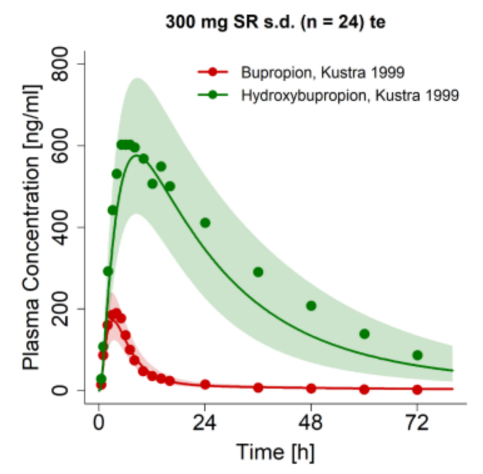

(h)

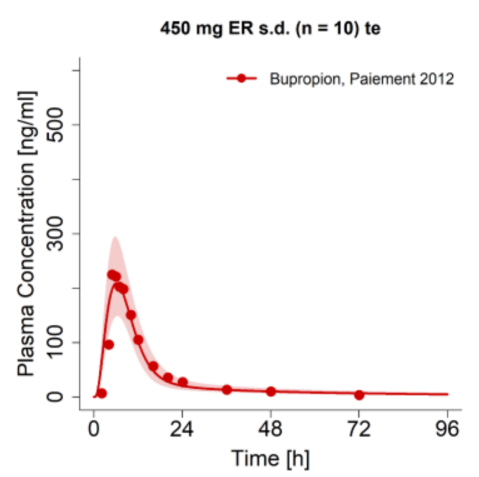

(c)

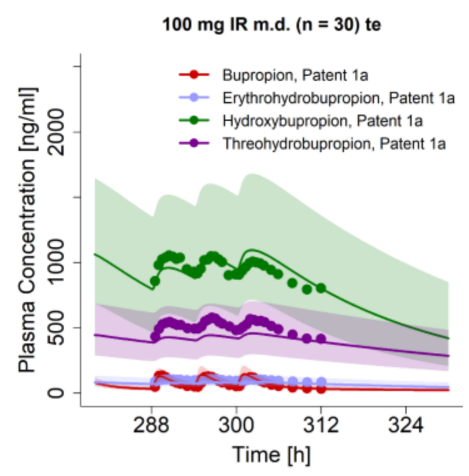

(f)

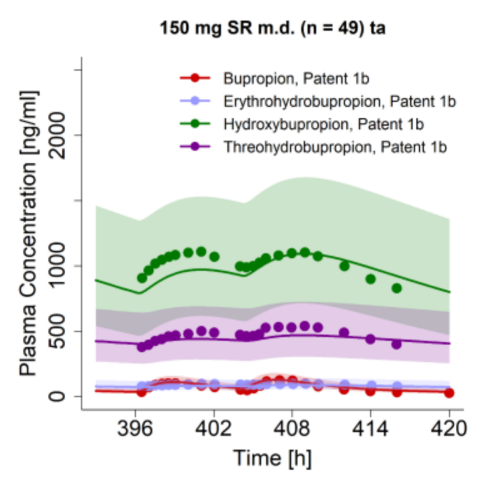

(i)

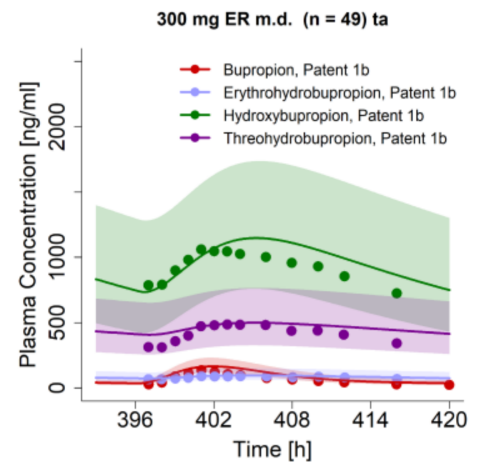

Figure 2. Predicted plasma concentration-time profiles of selected clinical studies from test and training datasets for bupropion, hydroxybupropion, erythro- and threohydrobupropion after application of single and multiple oral tablets with immediate release $(\mathbf{a}-\mathbf{c})$, sustained release $(\mathbf{d}-\mathbf{f})$ and extended release $(\mathbf{g}-\mathbf{i})$ kinetics compared to observed data $[3,28,32,51,54]$. The geometric means of the population predictions $(n=500)$ are shown as solid lines and corresponding observed data as dots (arithmetic mean \pm standard deviation, if available). The shaded areas indicate the geometric standard deviation. Detailed information on study protocols is provided in Table S2.1 of the Supplementary Materials. ER: extended release, IR: immediate release, m.d.: multiple dose, n: number of participants, s.d.: single dose, SR: sustained release, ta: training dataset, te: test dataset. 
Model performance is demonstrated in Figure 3 as comparisons of predicted to observed $\mathrm{AUC}_{\text {last }}$ (a) and $\mathrm{C}_{\max }$ values (b). Both training and test data were well predicted for all four compounds. In addition, Table 3 provides MRDs of plasma concentrationtime profiles and GMFEs of $\mathrm{AUC}_{\text {last }}$ and $\mathrm{C}_{\max }$ for the four compounds. With 119/124 of the predicted $A U C_{\text {last }}$ and 121/124 of the predicted $C_{\max }$ values within the 2-fold acceptance limits, total GMFEs of 1.31 (range $0.43-3.06$ ) for predicted $\mathrm{AUC}_{\text {last }}$ values and 1.29 (range 0.55-2.87) for $\mathrm{C}_{\max }$ values further confirmed an adequate model performance. Individual MRD and GMFE values for all plasma profiles are listed in Tables S2.3 and S2.4 in the Supplementary Materials.

(a)

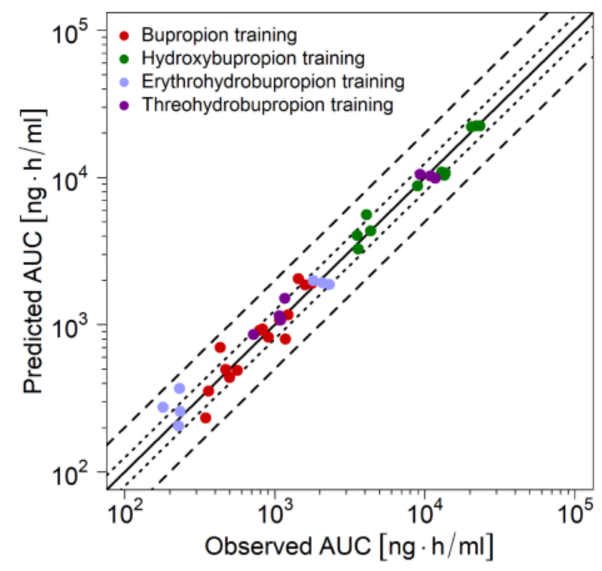

(c)

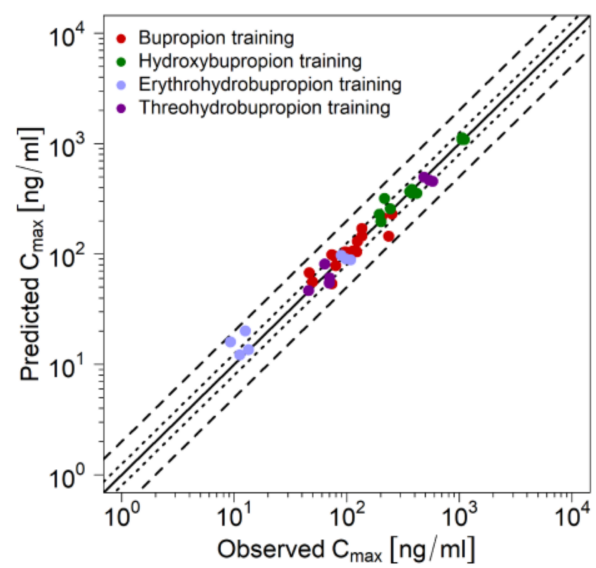

(b)

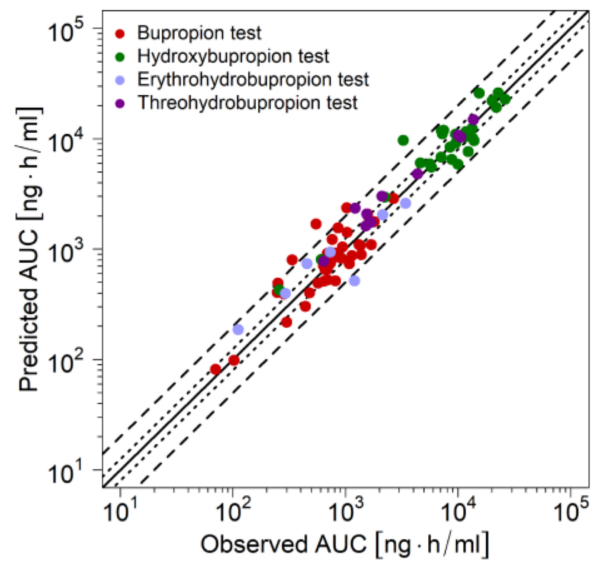

(d)

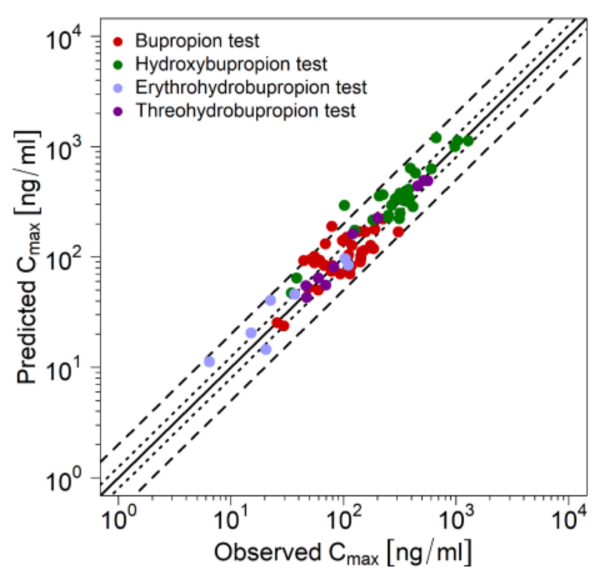

Figure 3. Goodness-of-fit plots of PK parameters for bupropion and metabolites. Predicted AUC of the training (a) and test dataset (b) as well as $\mathrm{C}_{\max }$ values of the training (c) and test dataset (d) compared to observed values. The solid line marks the line of identity, dotted lines indicate 1.25-fold, and dashed lines indicate 2-fold deviation. AUC: area under the plasma concentrationtime curve from the time of drug administration to the time of the last concentration measurement, $\mathrm{C}_{\text {max }}$ : maximum plasma concentration. 
Table 3. Summary of quantitative measures of model performance for bupropion and its metabolites, separated by training and test dataset.

\begin{tabular}{ccccccc}
\hline & \multicolumn{2}{c}{ Mean MRD } & \multicolumn{2}{c}{ Mean GMFE $_{\text {AUC }}$} & \multicolumn{2}{c}{ Mean GMFE $_{\text {Cmax }}$} \\
\hline & training & test & training & test & training & test \\
Bupropion & 1.62 & 1.90 & 1.20 & 1.42 & 1.20 & 1.41 \\
Hydroxybupropion & 1.16 & 1.30 & 1.14 & 1.34 & 1.10 & 1.32 \\
Erythrohydrobupropion & 1.48 & 1.38 & 1.25 & 1.46 & 1.26 & 1.38 \\
Threohydrobupropion & 1.36 & 1.21 & 1.36 & 1.23 & 1.17 & 1.30 \\
\hline Overall & \multicolumn{1}{c}{1.51} & \multicolumn{2}{c}{1.31} & 1.29 \\
Profiles with measure $\leq 2$ & $103 / 124$ & $119 / 124$ & $121 / 124$ \\
Range & $1.01-6.21$ & $0.43-3.06$ & \multicolumn{2}{c}{$0.55-2.87$} \\
\hline
\end{tabular}

AUC: area under the plasma concentration-time curve from the time of drug administration to the time of the last concentration measurement, $\mathrm{C}_{\max }$ : maximum plasma concentration, GMFE: geometric mean fold error, MRD: mean relative deviation.

Sensitivity analysis of a 14-day multiple dose simulation of either $100 \mathrm{mg}$ immediate release three times daily, $150 \mathrm{mg}$ sustained release twice daily, or $300 \mathrm{mg}$ extended release once daily, revealed that regardless of the bupropion formulation, the highest impact on bupropion AUC can be attributed to the fraction unbound of bupropion, a fixed literature value. Of the optimized parameters, the most impactful parameter was CYP2B6 kcat for immediate and sustained release formulations. For the extended release formulation, AUC was more sensitive to bupropion lipophilicity than to CYP2B6 kcat. A detailed assessment of model sensitivity is provided in Section 2.5.5 of the Supplementary Materials.

\subsection{DGI Modeling and Evaluation}

The developed model was extended to describe effects of polymorphism in the CYP2B6 gene on CYP2B6 activity and interaction with CYP2B6 perpetrator drugs. Most published studies only reported mean profiles of populations, often exhibiting multiple different genotypes, or only the respective AUC or HBup/Bup ratio of plasma AUC or single concentrations at specific time points after administration. However, plasma concentrationtime profiles of four genetic variants could be gathered from the literature. These included: $C Y P 2 B 6^{*} 1$ (or wildtype), CYP2B $6^{*} 4, C Y P 2 B 6^{*} 5$, and CYP2B $6^{*} 6$. Three studies reporting profiles of bupropion and hydroxybupropion were used for development of DGI predictions. Michaelis Menten constants $\left(\mathrm{K}_{\mathrm{M}}\right)$ were obtained from the literature and corrected for binding in the microsomal assay, if necessary. The rate constant $\mathrm{k}_{\text {cat }}$ was optimized for the $C Y P 2 B 6^{*} 6$ haplotype. Table 1 provides bupropion $\mathrm{K}_{\mathrm{M}}$ and $\mathrm{k}_{\mathrm{cat}}$ values for the implemented CYP2B6 alleles. Prediction of CYP2B6*4 heterozygous expression was simulated by splitting the implemented CYP2B6-mediated pathway in two clearance processes. In vitro parameters representing the $\mathrm{CYP} 2 \mathrm{~B} 6$ partition not produced by the $\mathrm{CYP} 2 \mathrm{~B} 6^{*} 4$ allele were assumed to be equal to parameters for homozygous expression of the respective allele (i.e., $C Y P 2 B 6^{*} 1 /{ }^{*} 1$ or $C Y P 2 B 6^{*} 6 /{ }^{*} 6$ ). For example, the $C Y P 2 B 6^{*} 1$ allele was simulated with a $\mathrm{K}_{\mathrm{M}}$ value of $25.80 \mu \mathrm{mol} / 1$ from the literature and half of the optimized $\left.C Y P 2 B 6^{*} 1\right|^{*} 1$ kcat value of $21.741 / \mathrm{min}$. Figure 4 demonstrates the performance of the bupropion DGI model with Figure $4 \mathrm{a}-\mathrm{c}$ illustrating model-based simulations of $150 \mathrm{mg}$ bupropion as an immediate release tablet alongside their respective observed profiles of three different polymorphisms in comparison to $\left.C Y P 2 B 6^{*} 1\right|^{*} 1$ (wildtype). The effect of DGIs, especially on hydroxybupropion plasma levels, was well described for rapid (CYP2B6*1|*4), normal (CYP2B $\left.6^{*} 1\right|^{*} 1$ or wildtype), intermediate $\left(\left.C Y P 2 B 6^{*} 1\right|^{*} 6\right)$ and poor metabolizers $\left(\left.C Y P 2 B 6^{*} 6\right|^{*} 6\right)$. Plots documenting the model performance for all modeled bupropion DGIs are provided in Figures S3.4.1 and S3.4.2 of the Supplementary Materials. Figure $4 \mathrm{~d}-\mathrm{e}$ shows predicted compared to observed DGI HBup/Bup ratios calculated for AUC (d) and $C_{\max }$ (e). Predicted DGI HBup/Bup ratios were in good agreement with observed ratios, with $20 / 20$ of DGI AUC $\mathrm{HBup}_{\text {BBup }}$ and $8 / 8$ of DGI $\mathrm{C}_{\max \text { HBup/Bup }}$ values within the 2 -fold acceptance limits and $18 / 20$ of DGI $A U C_{\text {HBup/Bup }}$ and $7 / 8$ of DGI $\mathrm{C}_{\text {max HBup/Bup }}$ values within the prediction success limits suggested by Guest et al. with 
1.25-fold variability [85]. Predicted and observed DGI $\mathrm{AUC}_{\mathrm{HBup} / \text { Bup }}$ ratios showed an overall GMFE of 1.25 (range 0.64-1.77) and DGI $C_{\max \text { HBup/Bup }}$ of 1.35 (range 0.41-1.29). Tables S3.3 and S3.4 of the Supplementary Materials list all calculated MRD and GMFE values of predicted and observed plasma concentration-time profiles and the corresponding AUC and $C_{\max }$ values along with the DGI HBup/Bup ratios.

(a)

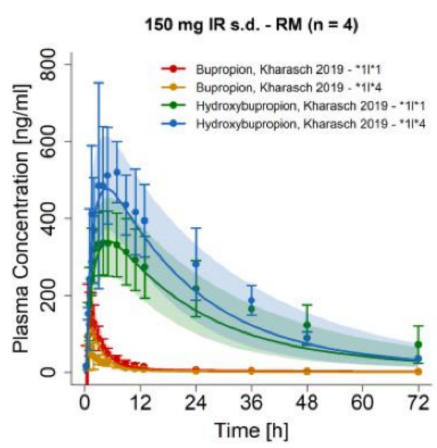

(d) (b)

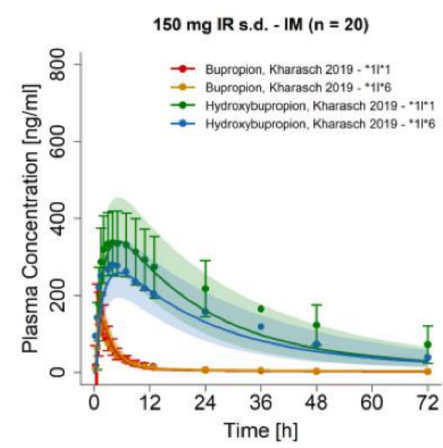

(c)

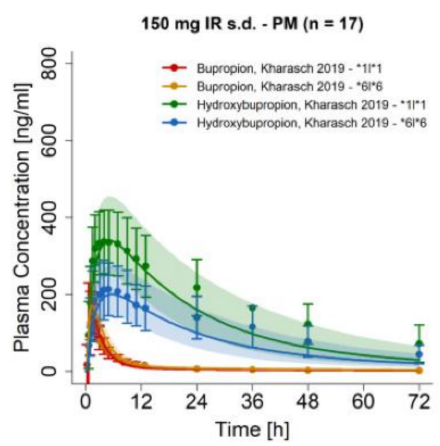

(e)
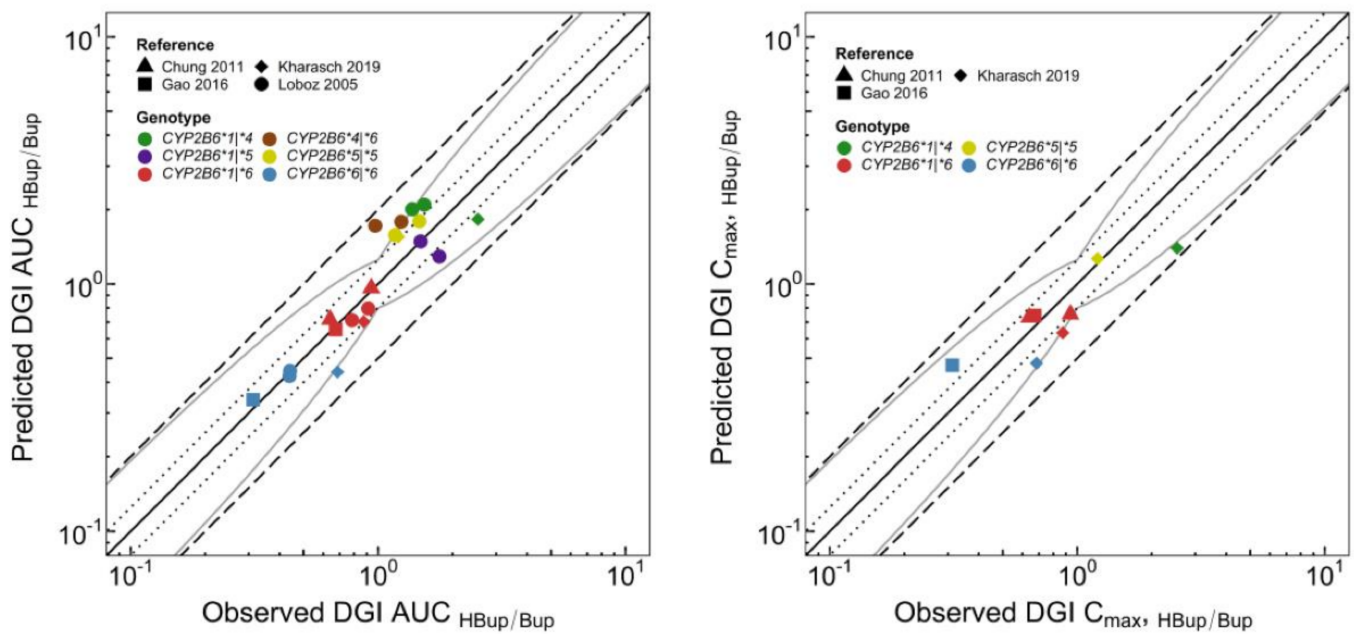

Figure 4. Bupropion CYP2B6 DGI model evaluation. Predicted compared to observed plasma concentration-time profiles are illustrated for $C Y P 2 B 6^{*} 1 / * 4(\mathbf{a}), C Y P 2 B 6^{*} 1 /{ }^{*} 6(\mathbf{b})$ and $C Y P 2 B 6^{*} 6 / * 6$ (c) genotypes [17] in comparison to the $C Y P 2 B 6^{*} 1 /{ }^{*} 1$ genotype (wildtype, $n=21$ ). The effects of respective genetic variants of CYP2B6 are shown in orange and blue for bupropion and hydroxybupropion, respectively; the corresponding profiles of the $C Y P 2 B 6^{*} 1 /{ }^{*} 1$ genotype are shown in red and green for bupropion and hydroxybupropion, respectively. The solid line illustrates the geometric mean of the population predictions $(n=500)$ and the shaded area the geometric standard deviation. Predicted compared to observed DGI effect ratios are shown for hydroxybupropion-bupropion ratios of AUC (d) and $C_{\max }(\mathbf{e})$ with different colors indicating the genotypes and different shapes the respective studies $[17,35,40,44]$. The straight solid line marks the line of identity, the curved solid lines show the prediction acceptance limits proposed by Guest et al. including 1.25-fold variability [85]. Dotted lines indicate 1.25-fold and dashed lines indicate 2-fold deviation. Details on the study protocols and DGI ratios are provided in the Supplementary Materials. AUC: area under the plasma concentration-time curve, $\mathrm{C}_{\max }$ : maximum plasma concentration, DGI: drug-gene interaction, HBup/Bup: hydroxybupropion-bupropion ratio, IM: intermediate metabolizer, IR: immediate release, PM: poor metabolize, RM: rapid metabolizer, s.d.: single dose.

\subsection{Bupropion DDI Modeling and Evaluation}

The bupropion DDI model was established and evaluated using a total of five clinical DDI studies with the perpetrator drugs fluvoxamine together with voriconazole (one study) and rifampicin (four studies). Details on the previously developed PBPK models for 
rifampicin [60], fluvoxamine [61], and voriconazole [59] are listed in the parameter tables in Section 4 of the Supplementary Materials.

The rifampicin-bupropion DDI was predicted as an induction of CYP2B6, CYP2C19, and UGT2B7 with interaction parameters obtained from the literature $[63,64,67]$. Additionally, competitive inhibition of CYP2B6 and UGT2B7 by rifampicin was included as well $[86,87]$.

The fluvoxamine-voriconazole-bupropion DDI was predicted as competitive inhibition of CYP2B6 and CYP2C19 metabolism by voriconazole and competitive inhibition of CYP2C19 by fluvoxamine. Literature CYP2C19 $\mathrm{K}_{\mathrm{i}}$ values were used for both fluvoxamine and voriconazole $[65,66]$. CYP2B6 $\mathrm{K}_{\mathrm{i}}$ of voriconazole was adjusted via parameter optimization.

Figure 5a-c illustrates predicted plasma concentration-time profiles before and during DDI scenarios in comparison to the corresponding observed data from clinical DDI studies. Induction by rifampicin and inhibition via fluvoxamine and voriconazole are shown for bupropion and hydroxybupropion plasma levels on linear scale for three representative studies (two for rifampicin DDIs with different bupropion release formulations and one for fluvoxamine and voriconazole). In Section 4 of the Supplementary Materials, predicted compared to observed profiles of all investigated rifampicin-bupropion DDIs are presented. In the DDI studies, $600 \mathrm{mg}$ rifampicin were administered daily with $150 \mathrm{mg}$ bupropion given once either as immediate release (Figure 5a) or sustained release tablets (shown in Figure 5b, Figure 6 and in Section 4 of the Supplementary Materials). Plasma concentration-time profiles during CYP2B6 inhibition were only provided in one DDI study with a single dose of bupropion as a cocktail capsule [22]. For the fluvoxaminevoriconazole-bupropion DDI scenario, fluvoxamine and voriconazole were administered concomitantly, $2 \mathrm{~h}$ before the bupropion cocktail capsule. Further details on regimens and population characteristics of the DDI studies are listed in Tables S4.4 and S4.5 of the Supplementary Materials.

HBup/Bup ratios were calculated via Equations (4) and (5) for AUC and $C_{\max }$ values and are depicted in Figure 5d-e. Here, 12/13 DDI AUC HBup/Bup $_{\text {and }}$ 6/6 DDI

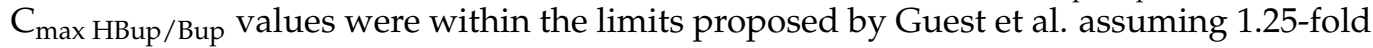
variability [85] with overall GMFE values of 1.23 (range 0.74-1.73) for DDI AUC $C_{\text {HBup/Bup }}$

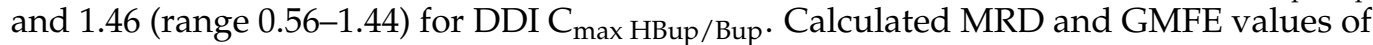
all predicted DDI studies are listed in Tables S4.6 and S4.7 of the Supplementary Materials. 
(a)

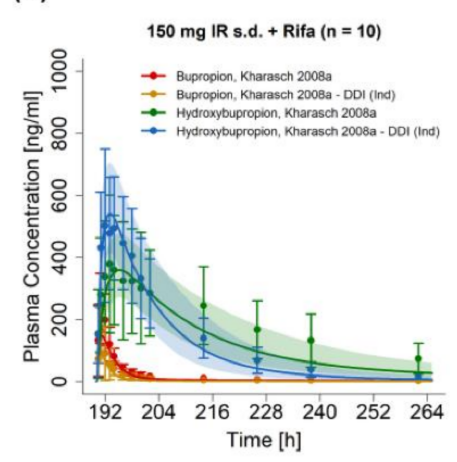

(d) (b)

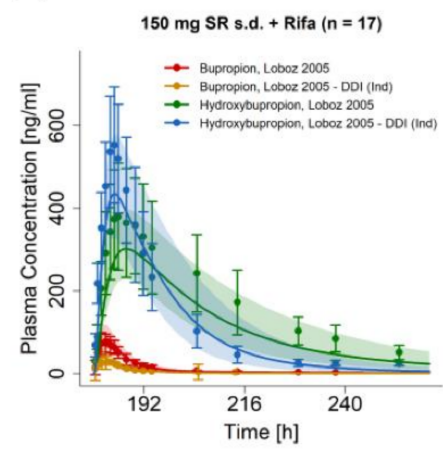

(e) (c)

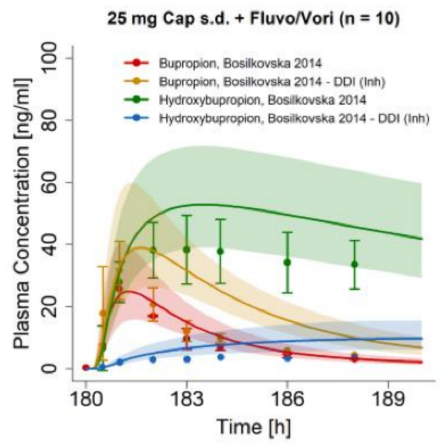

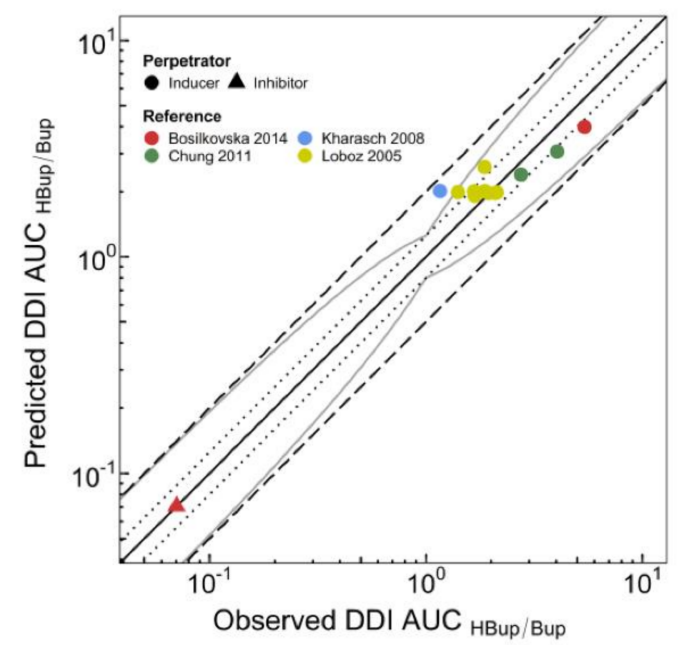

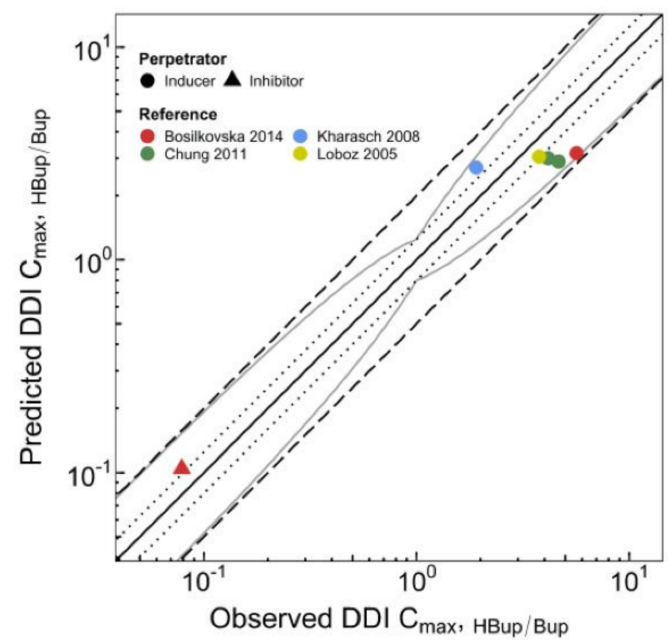

Figure 5. Victim drug plasma concentrations and DDI HBup/Bup ratios for AUC and $\mathrm{C}_{\max }$ of the modeled bupropion DDIs. Predicted compared to observed plasma concentration-time profiles of bupropion and hydroxybupropion are shown for interactions with rifampicin $(\mathbf{a}, \mathbf{b})$ as well as fluvoxamine and voriconazole (c). The profiles during administration of CYP2B6 perpetrator drugs are shown in orange and blue for bupropion and hydroxybupropion, respectively, and the corresponding profiles without DDI are shown in red and green for bupropion and hydroxybupropion, respectively. The solid line illustrates the geometric mean of the population predictions $(n=500)$ and the shaded area the geometric standard deviation. Predicted compared to observed effect ratio plots for the hydroxybupropion-bupropion ratios of AUC (d) and $C_{\max }(\mathbf{e})$ show data of four CYP2B6 inducer and one CYP2B6 inhibitor studies. Different shapes indicate the perpetrators and different colors the respective studies $[19,22,35,44]$. The straight solid line marks the line of identity; the curved solid lines show the prediction acceptance limits proposed by Guest et al. including 1.25-fold variability [85]. Dotted lines indicate 1.25-fold and dashed lines indicate 2-fold deviation. Details on the study protocols and the values of all DDI ratios are provided in the Supplementary Materials. AUC: area under the plasma concentration-time curve, Cap: capsule (Geneva Capsule [22]), $\mathrm{C}_{\text {max }}$ : maximum plasma concentration, DDI: drug-drug interaction, Fluvo/Vori: fluvoxamine and voriconazole, HBup/Bup: hydroxybupropion-bupropion ratio, Ind: inducer, Inh: inhibitor, IR: immediate release, Rifa: rifampicin, s.d.: single dose, SR: sustained release. 
(a)

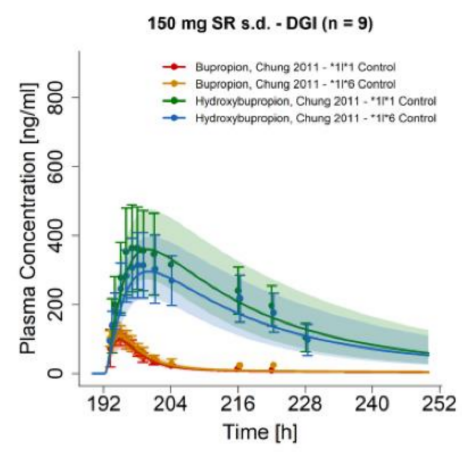

(d)

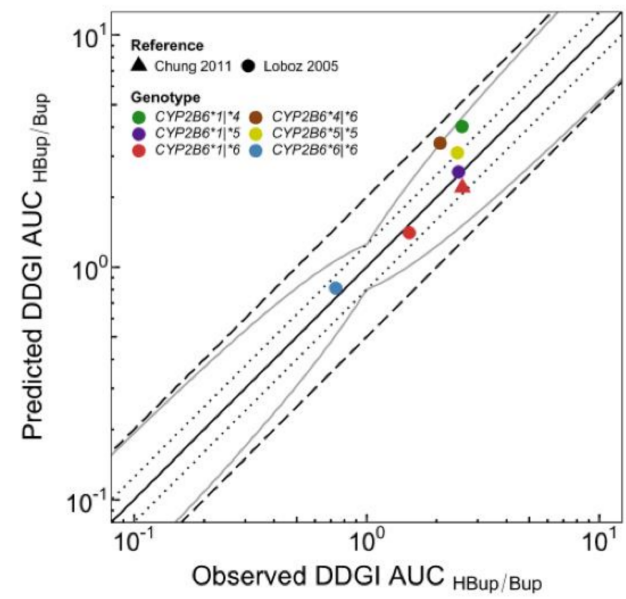

(b)

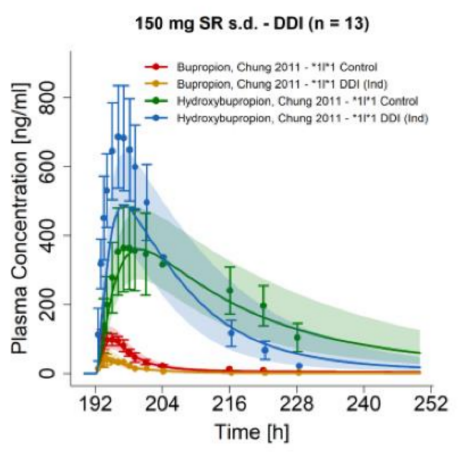

(e) (c)

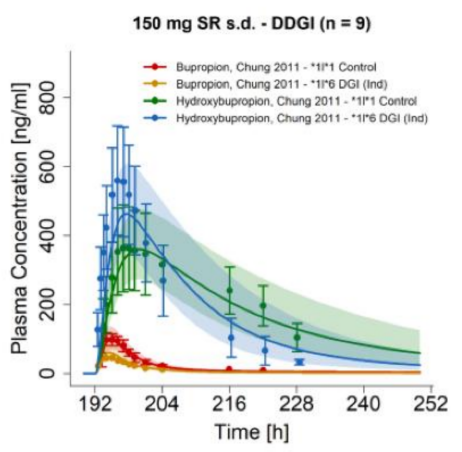

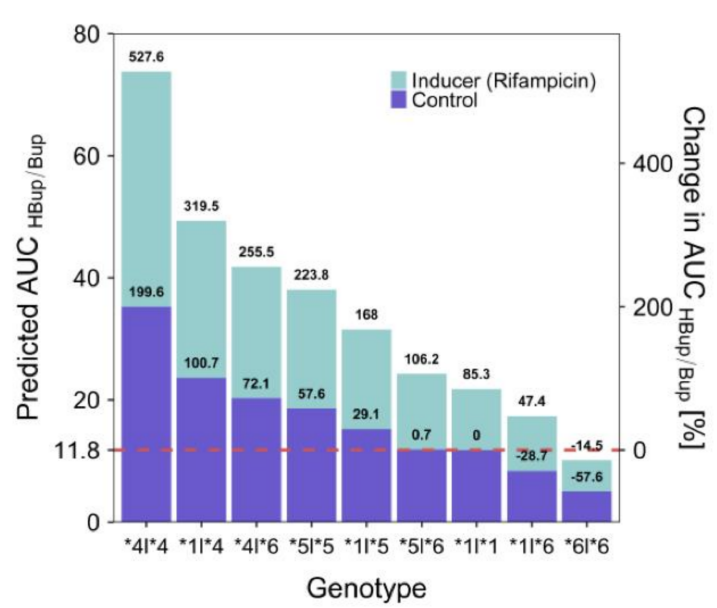

Figure 6. Rifampicin-bupropion CYP2B6 DDGI. Predicted compared to observed plasma concentration-time profiles are illustrated for the CYP2B6 bupropion DGI $\left(\left.C Y P 2 B 6^{*} 1\right|^{*} 6\right.$ compared to CYP2B $\left.\left.6^{*} 1\right|^{*} 1\right)$ (a), for rifampicin-bupropion DDI in individuals with the CYP2B $\left.6^{*} 1\right|^{*} 1$ genotype $(\mathbf{b})$ and for the rifampicin-bupropion DDGI for individuals with the $\left.C Y P 2 B 6^{*} 1\right|^{*} 6$ genotype compared to carriers of the $\left.C Y P 2 B 6^{*} 1\right|^{*} 1$ genotype (c). The predicted and observed plasma concentrations under the combined effects of CYP2B6 genetic polymorphism and perpetrators are shown in orange and blue, respectively, while the control is shown in red and green. The solid line illustrates the geometric mean of the population predictions $(n=500)$ and the shaded area the geometric standard deviation. Predicted compared to observed effect ratio plot for the hydroxybupropion-bupropion ratio of AUC values are shown for six different genotypes after rifampicin induction (d). Different colors indicate the genotypes and different shapes the respective studies $([35,44])$. The straight solid line marks the line of identity, the curved solid lines show the prediction acceptance limits proposed by Guest et al. including a 1.25-fold variability [85]. Dotted lines indicate 1.25-fold and dashed lines indicate 2-fold deviation. Predicted effects of rifampicin-bupropion DDGIs on the hydroxybupropion-bupropion AUC ratios were compared to $\left.C Y P 2 B 6^{*} 1\right|^{*} 1$ without co-administration of rifampicin (e). Details on study protocols and DDGI ratios are provided in the Supplementary Materials. AUC area under the plasma concentration-time curve, DGI: drug-gene interaction, DDI: drug-drug interaction, DDGI: drug drug gene interaction, HBup/Bup: hydroxybupropion-bupropion ratio, Ind: inducer, po: oral, s.d.: single dose, SR: sustained release.

\subsection{Bupropion DDGI Modeling and Evaluation}

DDGIs, combinations of DGIs and DDIs, were predicted for the polymorphisms CYP2B6*1, CYP2B6*4, CYP2B6*5, and CYP2B6*6 for bupropion intake in DDI scenarios with concomitant rifampicin administration. Rifampicin was administered in multiple oral doses of $600 \mathrm{mg}$ (daily) before a single oral dose of $150 \mathrm{mg}$ bupropion (sustained release) was administered $[35,67]$. One DDGI study reported plasma concentration-time profiles of bupropion and hydroxybupropion for $\left.C Y P 2 B 6^{*} 1\right|^{*} 1$ and $\left.C Y P 2 B 6^{*} 1\right|^{*} 6$ either with or without rifampicin. Figure $6 \mathrm{a}-\mathrm{c}$ shows predicted compared to observed profiles for a DGI in CYP2B6*6 heterozygous subjects (a), a DDI with rifampicin in CYP2B6 wildtype subjects 
(b), and a DDGI with rifampicin in CYP2B6*6 heterozygous subjects (c) compared to CYP2B6 wildtype subjects receiving bupropion solely. Furthermore, HBup/Bup ratios of $A U C_{\text {inf }}$ after rifampicin induction were reported for several CYP2B6 polymorphic individuals [44]. Figure $6 \mathrm{~d}$ illustrates predicted compared to observed DDGI $A U C_{\text {HBup/Bup }}$ values for several genetic variants of $C Y P 2 B 6$.

Figure 6e shows predicted $\mathrm{AUC}_{\mathrm{HBup} / \mathrm{Bup}}$ values for all possible allele combinations of the modeled $C Y P 2 B 6$ variants with or without rifampicin interaction. HBup/Bup ratios were decreased in carriers of the variant $C Y P 2 B 6^{*} 6$ allele. A homozygous $C Y P 2 B 6^{*} 6$ expression with inducer was predicted to be lower in CYP2B6 activity than wildtype CYP2B6 without inducer resulting in a $15 \%$ decrease in $\mathrm{AUC}_{\mathrm{HBup} / \mathrm{Bup}}$. CYP2B6 ${ }^{*} 5 \mathrm{I}^{*} 6$ individuals were predicted to exhibit $\mathrm{AUC}_{\mathrm{HBup} / \mathrm{Bup}}$ ratios similar to wildtype individuals, with or without inducer. The highest $\mathrm{AUC}_{\mathrm{HBup} / \mathrm{Bup}}$ was simulated for homozygous expression of the gene variant $C Y P 2 B 6^{*} 4$ after rifampicin intake. However, it should be noted that for predictions of the genotypes $\left.C Y P 2 B 6^{*} 4\right|^{*} 4$ and $C Y P 2 B 6^{*} 5 I^{*} 6$, no observed data for validation were available. In summary, DDGI predictions showed overall DDGI AUC $\mathrm{HBup}_{\text {Bup }}$ GMFE values of 1.27 (range $0.85-1.60$ ) with $7 / 7$ of the predicted DDGI $\mathrm{AUC}_{\mathrm{HBup} / \text { Bup }}$ within the acceptance limits of Guest et al., assuming 1.25-fold variability [85].

\section{Discussion}

In the presented work, a whole-body PBPK model of bupropion and its metabolites hydroxybupropion, threohydrobupropion and erythrohydrobupropion was built and evaluated to predict drug plasma concentrations over a wide dosing range (20-300 mg) for three different oral formulations. Furthermore, the model was extended to describe the effects of CYP2B6 DGIs, DDIs, and rifampicin-bupropion CYP2B6 DDGIs on the PK of bupropion and its metabolites.

So far, only one other bupropion PBPK model has been published yet [88]. Despite demonstrating reasonable performance, in comparison to the presented work, the model did not incorporate a similarly large amount of data for building and evaluation and did not reflect the effects of different genetic alterations of CYP2B6. These shortcomings, which we consider as necessary elements to qualify the bupropion PBPK model as a part of the CYP2B6 network, were addressed in our model.

Bupropion is predominantly metabolized to hydroxybupropion in the liver and, to some extent, also in the gut [10]. Even though CYP2B6 hydroxylation plays a major role in the metabolism of bupropion, the implementation of CYP2C19 as minor metabolic pathway was important to sufficiently describe the data including DDIs and DGIs [17,77]. In addition to CYP2B6 and CYP2C19 metabolism, carbonyl reductases transform bupropion to erythrohydrobupropion and threohydrobupropion [10]. In the presented model, the metabolic pathway along several carbonyl reductases was reduced to the rate-limiting enzymatic step via $11 \beta-H S D$ for the formation of erythrohydrobupropion and threohydrobupropion. Here, the respective $K_{M}$ values for all implemented enzymes could be informed from the literature. After a single dose of $150 \mathrm{mg}$ bupropion, the bupropion fractions metabolized were predicted as $58 \%, 28 \%$, and $13 \%$ via CYP2B6, 11 $\beta-H S D$, and CYP2C19, respectively (Figure S2.1.1 of the Supplementary Materials). Furthermore, the model predicts an extensive metabolism of bupropion (99\%) after complete absorption with small fractions excreted unchanged to urine and feces $(\sim 1 \%)$, which is consistent with the literature [9]. Reported bupropion fractions metabolized varied with measurements from in vitro clearance data of $56 \%$ or $12 \%$ for hydroxybupropion formation and $40 \%$ or $68 \%$ for threohydrobupropion formation [8,89], which are in reasonable agreement with predicted values.

Bupropion shows affinity to a variety of therapeutic targets, such as numerous acetylcholine receptors and dopamine and noradrenaline reuptake transporters [10]. Target binding was incorporated into our model as it improved the description of the concentrationtime profiles. To simplify the complex binding of bupropion to several targets, only binding to the noradrenaline reuptake transporter was implemented, as it covers the expression in all relevant organs, such as brain or gastro-intestinal tract, where noradrenaline and 
dopamine reuptake transporters, as well as nicotinic acetylcholine receptors are expected. The applied $\mathrm{K}_{\mathrm{D}}$ value is in good agreement with literature values describing binding or inhibition of the different relevant targets [78-80].

The bupropion metabolism is especially sensitive to genetic polymorphisms in CYP2B6 [17]. Unfortunately, documentation on genetic polymorphisms of participants was poor in most clinical studies. Either mean profiles of mixed populations were presented or no genotype information was reported. Nevertheless, gene variants CYP2B6*1, *4, *5, and ${ }^{*} 6$ were included in our model and described the available plasma concentration-time profiles of bupropion and hydroxybupropion sufficiently well. Dose adjustment guidelines for genetic polymorphisms have not been implemented yet. However, as hydroxybupropion might play an important role in the occurrence and onset of seizures after rapid bupropion absorption [10,12-14], the presented model could support a rational individualized CYP2B6 polymorphism-guided dose selection.

The presented DDI network includes interactions via CYP2B6, CYP2C19, and UGT2B7. The rifampicin-bupropion DDI covers the induction of CYP2B6, CYP2C19, and UGT2B7, with simultaneous competitive inhibition of CYP2B6 and UGT2B7. All rifampicin-bupropion interaction parameters were derived from the literature [45-48]. However, inhibition is relatively weak with inhibition constants $\left(\mathrm{K}_{\mathrm{i}}\right)$ of $118.50 \mu \mathrm{mol} / \mathrm{L}$ and $554.87 \mu \mathrm{mol} / \mathrm{L}$ for CYP2B6 and UGT2B7 [86,87] and presumably negligible; especially after multiple dose applications of rifampicin. For single dose administrations, rifampicin's inhibitory activity on bupropion could not be evaluated, due to a lack of clinical bupropion DDI data.

Voriconazole is a known CYP2B6 inhibitor that displayed interactions with bupropion and efavirenz [74]. The reported $K_{i}$ value of voriconazole was not strong enough to fully describe the observed in vivo effects. This seems reasonable, since the metabolite voriconazole N-oxide is also responsible for the inhibitory effect on CYP2B6 [90], but was not implemented in the published PBPK model [59]. Moreover, a polymorphism-dependent CYP2B6 inhibition of voriconazole was previously described for efavirenz hydroxylation, where lower $K_{i}$ values were reported for $C Y P 2 B 6^{*} 6$ than for $C Y P 2 B 6^{*} 1$ [74]. In the DDI study conducted by Bosilkovska et al. [22], six of 10 subjects exhibited a CYP2B6*6 polymorphism, which could potentially explain a deviation in prediction. Due to the lack of relevant clinical data, the $\mathrm{K}_{\mathrm{i}}$ value of voriconazole for CYP2B6 had to be optimized and could not be validated yet. Hence, further in vitro studies are needed to optimize and evaluate the voriconazole DDI. Inhibition of CYP2C19 was implemented, as fluvoxamine and voriconazole are listed as strong and weak inhibitors for CYP2C19 by the FDA, respectively [16]. As bupropion is also a known CYP2D6 inhibitor, we assumed that the inhibitory effect on CYP2D6-mediated fluvoxamine metabolism is negligibly small, as fluvoxamine is given $2 \mathrm{~h}$ prior to bupropion administration, and as bupropion's strong CYP2D6 inhibition potential is predominately attributed to its metabolites and a CYP2D6 downregulation after long-term bupropion intake [91].

The model correctly predicted DDGI plasma profiles of bupropion co-administered with rifampicin in $C Y P 2 B 6^{*} 6$ heterozygous subjects. Furthermore, DDGI model performance was successfully evaluated by comparison of predicted and reported HBup/Bup AUC ratios. Subsequently, potential DDGIs were simulated for combinations of the genetic $C Y P 2 B 6$ variants $C Y P 2 B 6^{*} 1, C Y P 2 B 6^{*} 4, C Y P 2 B 6^{*} 5$, and $C Y P 2 B 6^{*} 6$. The simulated scenarios illustrate the models' potential to investigate the effect of DDGIs on bupropion and hydroxybupropion plasma levels. Whether the simulated DDGI combinations lead to the predicted changes in HBup/Bup ratios, especially the profound increase in rapid metabolizers receiving the CYP2B6 inducer rifampicin, should be carefully evaluated in clinical studies. Moreover, pharmacological implications of bupropion intake, with or without perpetrator, in CYP2B6 polymorphic patients, are still unclear. While clinical efficacy or tolerability can be correlated to plasma levels of bupropion or its metabolites, guidelines regarding bupropion dosing have yet to be established. Our presented model demonstrated its flexibility in simulations of various DDGI scenarios and can be applied to 
develop rational dosing recommendations for bupropion drug labeling or clinical study design.

\section{Conclusions}

A comprehensive parent-metabolite PBPK model of bupropion including whole-body PBPK models of bupropion and the metabolites hydroxybupropion, erythrohydrobupropion, and threohydrobupropion was developed. Bupropion pharmacokinetics were thoroughly described for tablets with different release formulations in single and multiple dose regimens. The established CYP2B6 network incorporates reliable prediction of DGIs with several polymorphisms, DDIs and DDGIs as combinations of DGIs and DDIs. A transparent and detailed documentation of the model development and performance further underlines the model quality. The final PBPK model files are freely available in the Open Systems Pharmacology repository (www.open-systems-pharmacology.org, December 2020) [26] to assist the development of bupropion dosing guidelines and to support DDI studies in drug discovery and development.

Supplementary Materials: The following are available at https:/ /www.mdpi.com/1999-4923/13/3 /331/s1, Electronic Supplementary Materials: A comprehensive reference manual, providing documentation of the complete model performance assessment.

Author Contributions: Conceptualization, F.Z.M., L.M.F., N.H., D.S. and T.L.; funding acquisition, T.L.; investigation, F.Z.M., L.M.F., N.H., D.S. and T.L.; visualization, F.Z.M.; writing—original draft, F.Z.M.; writing-review and editing, F.Z.M., L.M.F., N.H., D.S. and T.L. All authors have read and agreed to the published version of the manuscript.

Funding: This work has received support from the project "Open-source modeling framework for automated quality control and management of complex life science system models" (OSMOSES), which is funded by the German Federal Ministry of Education and Research (BMBF, grant ID:031L0161C). We acknowledge support by the Deutsche Forschungsgemeinschaft (DFG, German Research Foundation) and Saarland University within the funding program Open Access Publishing.

Institutional Review Board Statement: Not applicable.

Informed Consent Statement: Not applicable.

Data Availability Statement: All modeling files including utilized clinical study data can be found at https:/ / github.com/Open-Systems-Pharmacology (accessed on 31 December 2020).

Acknowledgments: We thank Elizaveta Burgakova for her work during her internship at Saarland University.

Conflicts of Interest: Thorsten Lehr has received research grants from the German Federal Ministry of Education and Research (grant 031L0161C). Fatima Zahra Marok, Laura Maria Fuhr, Nina Hanke and Dominik Selzer declare no conflict of interest. The funders had no role in the design of the study; in the collection, analyses, or interpretation of data; in the writing of the manuscript, or in the decision to publish the results.

\section{References}

1. Fava, M.; Rush, A.J.; Thase, M.E.; Clayton, A.; Stahl, S.M.; Pradko, J.F.; Johnston, J.A. 15 Years of Clinical Experience with Bupropion HCl. Prim. Care Companion J. Clin. Psychiatry 2005, 07, 106-113. [CrossRef] [PubMed]

2. DrugStats, C. Multum Therapeutic Class Comparison, United States, 2018-Total Prescribtions in 2018. Available online: https://clincalc.com/DrugStats/TC/PsychotherapeuticAgents (accessed on 17 December 2020).

3. Connarn, J.N.; Flowers, S.; Kelly, M.; Luo, R.; Ward, K.M.; Harrington, G.; Moncion, I.; Kamali, M.; McInnis, M.; Feng, M.R.; et al. Pharmacokinetics and Pharmacogenomics of Bupropion in Three Different Formulations with Different Release Kinetics in Healthy Human Volunteers. AAPS J. 2017, 19, 1513-1522. [CrossRef] [PubMed]

4. Fokina, V.M.; Xu, M.; Rytting, E.; Abdel-Rahman, S.Z.; West, H.; Oncken, C.; Clark, S.M.; Ahmed, M.S.; Hankins, G.D.V.; Nanovskaya, T.N. Pharmacokinetics of bupropion and its pharmacologically active metabolites in pregnancy. Drug Metab. Dispos. 2016, 44, 1832-1838. [CrossRef]

5. Slemmer, J.E.; Martin, B.R.; Damaj, M.I. Bupropion is a nicotinic antagonist. J. Pharmacol. Exp. Ther. 2000, 295, 321-327. [PubMed] 
6. Stahl, S.M.; Pradko, J.F.; Haight, B.R.; Modell, J.G.; Rockett, C.B.; Learned-Coughlin, S. A Review of the Neuropharmacology of Bupropion, a Dual Norepinephrine and Dopamine Reuptake Inhibitor. Prim. Care Companion J. Clin. Psychiatry 2004, 06, 159-166. [CrossRef]

7. Eriksson, O.; Långström, B.; Josephsson, R. Assessment of receptor occupancy-over-time of two dopamine transporter inhibitors by [11C]CIT and target controlled infusion. Ups. J. Med. Sci. 2011, 116, 100-106. [CrossRef]

8. Sager, J.E.; Price, L.S.L.; Isoherranen, N. Stereoselective Metabolism of Bupropion to OH-bupropion, Threohydrobupropion, Erythrohydrobupropion, and 4'-OH-bupropion in vitro. Drug Metab. Dispos. 2016, 44, 1709-1719. [CrossRef]

9. Biovial Corporation. Wellbutrin XL ®®(Bupropion Hydrochloride Extended-Release Tablets)—Medicine Guide. Available online: https:/ / www.accessdata.fda.gov/drugsatfda_docs/label/2010/021515s022lbl.pdf (accessed on 22 January 2021).

10. Costa, R.; Oliveira, N.G.; Dinis-Oliveira, R.J. Pharmacokinetic and pharmacodynamic of bupropion: Integrative overview of relevant clinical and forensic aspects. Drug Metab. Rev. 2019, 51, 293-313. [CrossRef] [PubMed]

11. Johnston, J.A.; Fiedler-Kelly, J.; Glover, E.D.; Sachs, D.P.L.; Grasela, T.H.; De Veaugh-Geiss, J. Relationship between drug exposure and the efficacy and safety of bupropion sustained release for smoking cessation. Nicotine Tob. Res. 2001, 3, 131-140. [CrossRef]

12. Silverstone, P.H.; Williams, R.; McMahon, L.; Fleming, R.; Fogarty, S. Convulsive liability of bupropion hydrochloride metabolites in Swiss albino mice. Ann. Gen. Psychiatry 2008, 7, 19. [CrossRef] [PubMed]

13. Davidson, J. Seizures and bupropion: A review. J. Clin. Psychiatry 1989, 50, 256-261. [CrossRef]

14. Dunner, D.L.; Zisook, S.; Billow, A.A.; Batey, S.R.; Johnston, J.A.; Ascher, J.A. A Prospective Safety Surveillance Study for Bupropion Sustained-Release in the Treatment of Depression. J. Clin. Psychiatry 1998, 59, 366-373. [CrossRef]

15. Gufford, B.T.; Lu, J.B.L.; Metzger, I.F.; Jones, D.R.; Desta, Z. Stereoselective glucuronidation of bupropion metabolites in vitro and in vivo. Drug Metab. Dispos. 2016, 44, 544-553. [CrossRef]

16. U.S. Food and Drug Administration. Drug Development and Drug Interactions: Table of Substrates, Inhibitors and Inducers. FDA. Available online: https://www.fda.gov/drugs/drug-interactions-labeling/drug-development-and-drug-interactionstable-substrates-inh (accessed on 31 December 2020).

17. Kharasch, E.D.; Crafford, A. Common Polymorphisms of CYP2B6 Influence Stereoselective Bupropion Disposition. Clin. Pharmacol. Ther. 2019, 105, 142-152. [CrossRef]

18. Masters, A.R.; Gufford, B.T.; Lu, J.B.L.; Metzger, I.F.; Jones, D.R.; Desta, Z. Chiral Plasma Pharmacokinetics and Urinary Excretion of Bupropion and Metabolites in Healthy Volunteers. J. Pharmacol. Exp. Ther. 2016, 358, 230-238. [CrossRef] [PubMed]

19. Khrarasch, E.D.; Bedynek, P.S.; Walker, A.; Whittington, D.; Hoffer, C.; and Park, S. Mechanism of ritonavir changes in methadone pharmacokinetics and pharmacodynamics. II. Ritonavir effects on CYP3A and P-glycoprotein activities. Clin. Pharmacol. Ther. 2008, 84, 506-512. [CrossRef] [PubMed]

20. Hogeland, G.W.; Swindells, S.; McNabb, J.C.; Kashuba, A.D.M.; Yee, G.C.; Lindley, C.M. Lopinavir/ritonavir Reduces Bupropion Plasma Concentrations in Healthy Subjects. Clin. Pharmacol. Ther. 2007, 81, 69-75. [CrossRef] [PubMed]

21. Turpeinen, M.; Tolonen, A.; Uusitalo, J.; Jalonen, J.; Pelkonen, O.; Laine, K. Effect of clopidogrel and ticlopidine on cytochrome P450 2B6 activity as measured by bupropion hydroxylation. Clin. Pharmacol. Ther. 2005, 77, 553-559. [CrossRef]

22. Bosilkovska, M.; Samer, C.F.; Déglon, J.; Rebsamen, M.; Staub, C.; Dayer, P.; Walder, B.; Desmeules, J.A.; Daali, Y. Geneva Cocktail for Cytochrome P450 and P-Glycoprotein Activity Assessment Using Dried Blood Spots. Clin. Pharmacol. Ther. 2014, 96, 349-359. [CrossRef]

23. Reese, M.J.; Wurm, R.M.; Muir, K.T.; Generaux, G.T.; St. John-Williams, L.; Mcconn, D.J. An in Vitro Mechanistic Study to Elucidate the Desipramine/Bupropion Clinical Drug-Drug Interaction. Drug Metab. Dispos. 2008, 36, 1198-1201. [CrossRef]

24. Desta, Z.; Gammal, R.S.; Gong, L.; Whirl-Carrillo, M.; Gaur, A.H.; Sukasem, C.; Hockings, J.; Myers, A.; Swart, M.; Tyndale, R.F.; et al. Clinical Pharmacogenetics Implementation Consortium (CPIC) Guideline for CYP2B6 and Efavirenz-Containing Antiretroviral Therapy. Clin. Pharmacol. Ther. 2019, 106, 726-733. [CrossRef]

25. Wojtyniak, J.; Selzer, D.; Schwab, M.; Lehr, T. Physiologically Based Precision Dosing Approach for Drug-Drug-Gene Interactions: A Simvastatin Network Analysis. Clin. Pharmacol. Ther. 2020, cpt.2111. [CrossRef]

26. Lippert, J.; Burghaus, R.; Edginton, A.; Frechen, S.; Karlsson, M.; Kovar, A.; Lehr, T.; Milligan, P.; Nock, V.; Ramusovic, S.; et al. Open Systems Pharmacology Community-An Open Access, Open Source, Open Science Approach to Modeling and Simulation in Pharmaceutical Sciences. CPT Pharmacomet. Syst. Pharmacol. 2019, 8, 878-882. [CrossRef] [PubMed]

27. Wojtyniak, J.; Britz, H.; Selzer, D.; Schwab, M.; Lehr, T. Data Digitizing: Accurate and Precise Data Extraction for Quantitative Systems Pharmacology and Physiologically-Based Pharmacokinetic Modeling. CPT Pharmacomet. Syst. Pharmacol. 2020, 9, 322-331. [CrossRef] [PubMed]

28. Hesse, L.M.; Greenblatt, D.J.; von Moltke, L.L.; Court, M.H. Ritonavir Has Minimal Impact on the Pharmacokinetic Disposition of a Single Dose of Bupropion Administered to Human Volunteers. J. Clin. Pharmacol. 2006, 46, 567-576. [CrossRef]

29. Yamazaki, T.; Desai, A.; Goldwater, R.; Han, D.; Howieson, C.; Akhtar, S.; Kowalski, D.; Lademacher, C.; Pearlman, H.; Rammelsberg, D.; et al. Pharmacokinetic Effects of Isavuconazole Coadministration With the Cytochrome P450 Enzyme Substrates Bupropion, Repaglinide, Caffeine, Dextromethorphan, and Methadone in Healthy Subjects. Clin. Pharmacol. Drug Dev. 2017, 6, 54-65. [CrossRef]

30. Posner, J.; Bye, A.; Jeal, S.; Peck, A.W.; Whiteman, P. Alcohol and bupropion pharmacokinetics in healthy male volunteers. Eur. J. Clin. Pharmacol. 1984, 26, 627-630. [CrossRef] [PubMed] 
31. Posner, J.; Bye, A.; Dean, K.; Peck, A.W.; Whiteman, P.D. The disposition of bupropion and its metabolites in healthy male volunteers after single and multiple doses. Eur. J. Clin. Pharmacol. 1985, 29, 97-103. [CrossRef]

32. Oberegger, W.; Eradiri, O.; Zhou, F.; Maes, P. Modified Release Tablet of Bupropion Hydrochloride. U.S. Patent No. US 2006/0228415 A1, 12 October 2006.

33. Kharasch, E.D.; Mitchell, D.; Coles, R.; Blanco, R. Rapid Clinical Induction of Hepatic Cytochrome P4502B6 Activity by Ritonavir. Antimicrob. Agents Chemother. 2008, 52, 1663-1669. [CrossRef]

34. Benowitz, N.L.; Zhu, A.Z.X.; Tyndale, R.F.; Dempsey, D.; Jacob, P. Influence of CYP2B6 genetic variants on plasma and urine concentrations of bupropion and metabolites at steady state. Pharmacogenet. Genom. 2013, 23, 135-141. [CrossRef]

35. Chung, J.Y.; Cho, J.Y.; Lim, H.S.; Kim, J.R.; Yu, K.S.; Lim, K.S.; Shin, S.G.; Jang, I.J. Effects of pregnane X receptor (NR1I2) and CYP2B6 genetic polymorphisms on the induction of bupropion hydroxylation by rifampin. Drug Metab. Dispos. 2011, 39, 92-97. [CrossRef]

36. Dennison, J.; Puri, A.; Warrington, S.; Endo, T.; Adeloye, T.; Johnston, A. Amenamevir: Studies of Potential CYP2C8- and CYP2B6Mediated Pharmacokinetic Interactions with Montelukast and Bupropion in Healthy Volunteers. Clin. Pharmacol. Drug Dev. 2018, 7, 860-870. [CrossRef]

37. Fan, L.; Wang, J.C.; Jiang, F.; Tan, Z.R.; Chen, Y.; Li, Q.; Zhang, W.; Wang, G.; Lei, H.P.; Hu, D.L.; et al. Induction of cytochrome P450 2B6 activity by the herbal medicine baicalin as measured by bupropion hydroxylation. Eur. J. Clin. Pharmacol. 2009, 65, 403-409. [CrossRef] [PubMed]

38. Farid, N.A.; Payne, C.D.; Ernest, C.S.; Li, Y.G.; Winters, K.J.; Salazar, D.E.; Small, D.S. Prasugrel, a new thienopyridine antiplatelet drug, weakly inhibits cytochrome P450 2B6 in humans. J. Clin. Pharmacol. 2008, 48, 53-59. [CrossRef] [PubMed]

39. Gao, L.C.; Huang, X.; Tan, Z.R.; Fan, L.; Zhou, H.H. The effects of sodium ferulate on the pharmacokinetics of bupropion and its active metabolite in healthy men. Eur. Rev. Med. Pharmacol. Sci. 2012, 16, 1192-1196.

40. Gao, L.-C.; Liu, F.-Q.; Yang, L.; Cheng, L.; Dai, H.-Y.; Tao, R.; Cao, S.P.; Wang, D.; Tang, J. The P450 oxidoreductase (POR) rs2868177 and cytochrome P450 (CYP) 2B6*6 polymorphisms contribute to the interindividual variability in human CYP2B6 activity. Eur. J. Clin. Pharmacol. 2016, 72, 1205-1213. [CrossRef]

41. Hsyu, P.-H.; Singh, A.; Giargiari, T.D.; Dunn, J.A.; Ascher, J.A.; Johnston, J.A. Pharmacokinetics of Bupropion and its Metabolites in Cigarette Smokers versus Nonsmokers. J. Clin. Pharmacol. 1997, 37, 737-743. [CrossRef]

42. Lei, H.; Ji, W.; Lin, J.; Chen, H.; Tan, Z.; Hu, D.; Liu, L.; Zhou, H. Effects of Ginkgo biloba extract on the pharmacokinetics of bupropion in healthy volunteers. Br. J. Clin. Pharmacol. 2009, 68, 201-206. [CrossRef]

43. Lei, H.-P.; Yu, X.-Y.; Xie, H.-T.; Li, H.-H.; Fan, L.; Dai, L.-L.; Chen, Y.; Zhou, H.-H. Effect of St. John's wort supplementation on the pharmacokinetics of bupropion in healthy male Chinese volunteers. Xenobiotica 2010, 40, 275-281. [CrossRef]

44. Loboz, K.; Gross, A.; Williams, K.; Liauw, W.; Day, R.; Blievernicht, J.; Zanger, U.; McLachlan, A. Cytochrome P450 2 B6 activity as measured by bupropion hydroxylation: Effect of induction by rifampin and ethnicity. Clin. Pharmacol. Ther. 2006, 80, 75-84. [CrossRef]

45. Palovaara, S.; Pelkonen, O.; Uusitalo, J.; Laine, K. Inhibition of cytochrome P450 2B6 activity by hormone replacement therapy and oral contraceptive as measured by bupropion hydroxylation. Clin. Pharmacol. Ther. 2003, 74, 326-333. [CrossRef]

46. Li, B.; Nangia, A.; Ming, C.; Cheng, X.X. Controlled Release Oral Dosage Form. U.S. Patent No. US 8,545,880 B2, 30 September 2013.

47. Qin, W.; Zhang, W.; Liu, Z.; Chen, X.; Tan, Z.; Hu, D.; Wang, D.; Fan, L.; Zhou, H. Rapid clinical induction of bupropion hydroxylation by metamizole in healthy Chinese men. Br. J. Clin. Pharmacol. 2012, 74, 999-1004. [CrossRef] [PubMed]

48. Robertson, S.M.; Maldarelli, F.; Natarajan, V.; Formentini, E.; Alfaro, R.M.; Penzak, S.R. Efavirenz induces CYP2B6-mediated hydroxylation of bupropion in healthy subjects. J. Acquir. Immune Defic. Syndr. 2008, 49, 513-519. [CrossRef]

49. Turpeinen, M.; Koivuviita, N.; Tolonen, A.; Reponen, P.; Lundgren, S.; Miettunen, J.; Metsärinne, K.; Rane, A.; Pelkonen, O.; Laine, K. Effect of renal impairment on the pharmacokinetics of bupropion and its metabolites. Br. J. Clin. Pharmacol. 2007, 64, 165-173. [CrossRef] [PubMed]

50. Turpeinen, M.; Uusitalo, J.; Lehtinen, T.; Kailajärvi, M.; Pelkonen, O.; Vuorinen, J.; Tapanainen, P.; Stjernschantz, C.; Lammintausta, R.; Scheinin, M. Effects of Ospemifene on Drug Metabolism Mediated by Cytochrome P450 Enzymes in Humans in Vitro and in Vivo. Int. J. Mol. Sci. 2013, 14, 14064-14075. [CrossRef] [PubMed]

51. Kustra, R.; Corrigan, B.; Dunn, J.; Duncan, B.; Hsyu, P.H. Lack of effect of cimetidine on the pharmacokinetics of sustained-release bupropion. J. Clin. Pharmacol. 1999, 39, 1184-1188.

52. Schmid, Y.; Rickli, A.; Schaffner, A.; Duthaler, U.; Grouzmann, E.; Hysek, C.M.; Liechti, M.E. Interactions between Bupropion and 3,4-Methylenedioxymethamphetamine in Healthy Subjects. J. Pharmacol. Exp. Ther. 2015, 353, 102-111. [CrossRef] [PubMed]

53. Woodcock, J.; Khan, M.; Yu, L.X. Withdrawal of Generic Budeprion for Nonbioequivalence. N. Engl. J. Med. 2012, 367, $2461-2463$. [CrossRef]

54. Paiement, N.; Noonan, P.K.; González, M.A.; Zerbe, H. Steady State Plasma Levels of Bupropion After Administration of $3 \times 150$ Mg Extended Release Reference Tablets and Switching to 1x450 Mg Extended Release 450ER Tablets. Int. J. Clin. Pharmacol. Toxicol. 2012, 1, 26-31. [CrossRef]

55. Bosilkovska, M.; Samer, C.; Déglon, J.; Thomas, A.; Walder, B.; Desmeules, J.; Daali, Y. Evaluation of Mutual Drug-Drug Interaction within Geneva Cocktail for Cytochrome P450 Phenotyping using Innovative Dried Blood Sampling Method. Basic Clin. Pharmacol. Toxicol. 2016, 119, 284-290. [CrossRef] 
56. Findlay, J.W.A.; Van Wyck Fleet, J.; Smith, P.G.; Butz, R.F.; Hinton, M.L.; Blum, M.R.; Schroeder, D.H. Pharmacokinetics of bupropion, a novel antidepressant agent, following oral administration to healthy subjects. Eur. J. Clin. Pharmacol. 1981, 21,127-135. [CrossRef]

57. Zahner, C.; Kruttschnitt, E.; Uricher, J.; Lissy, M.; Hirsch, M.; Nicolussi, S.; Krähenbühl, S.; Drewe, J. No Clinically Relevant Interactions of St. John's Wort Extract Ze 117 Low in Hyperforin with Cytochrome P450 Enzymes and P-glycoprotein. Clin. Pharmacol. Ther. 2019, 106, 432-440. [CrossRef]

58. Open Systems Pharmacology Suite Community. PK-Sim®®Ontogeny Database Documentation, Version 7.3. Available online: https://github.com/Open-Systems-Pharmacology/OSPSuite.Documentation/blob/master/PK-Sim\%20Ontogeny \%20 Database\%20Version\%207.3.pdf (accessed on 31 December 2020).

59. Li, X.; Frechen, S.; Moj, D.; Lehr, T.; Taubert, M.; Hsin, C.-H.; Mikus, G.; Neuvonen, P.J.; Olkkola, K.T.; Saari, T.I.; et al. A Physiologically Based Pharmacokinetic Model of Voriconazole Integrating Time-Dependent Inhibition of CYP3A4, Genetic Polymorphisms of CYP2C19 and Predictions of Drug-Drug Interactions. Clin. Pharmacokinet. 2020, 59, 781-808. [CrossRef]

60. Hanke, N.; Frechen, S.; Moj, D.; Britz, H.; Eissing, T.; Wendl, T.; Lehr, T. PBPK Models for CYP3A4 and P-gp DDI prediction: A modeling network of rifampicin, itraconazole, clarithromycin, midazolam, alfentanil, and digoxin. CPT Pharmacometrics Syst. Pharmacol. 2018, 7, 647-659. [CrossRef]

61. Britz, H.; Hanke, N.; Volz, A.; Spigset, O.; Schwab, M.; Eissing, T.; Wendl, T.; Frechen, S.; Lehr, T. Physiologically-based pharmacokinetic models for CYP1A2 drug-drug interaction prediction: A modeling network of fluvoxamine, theophylline, caffeine, rifampicin, and midazolam. CPT Pharmacomet. Syst. Pharmacol. 2019, 8, 296-307. [CrossRef] [PubMed]

62. Langenbucher, F. Linearization of dissolution rate curves by the Weibull distribution. J. Pharm. Pharmacol. 1972, $24,979-981$. [CrossRef]

63. Ramamoorthy, A.; Liu, Y.; Philips, S.; Desta, Z.; Lin, H.; Goswami, C.; Gaedigk, A.; Li, L.; Flockhart, D.A.; Skaar, T.C. Regulation of microRNA expression by rifampin in human hepatocytes. Drug Metab. Dispos. 2013, 41, 1763-1768. [CrossRef] [PubMed]

64. Zhang, J.G.; Patel, R.; Clark, R.J.; Ho, T.; Trisdale, S.K.; Fang, Y.; Stresser, D.M. Effect of Fifteen CYP3A4 in vitro Inducers on the Induction of Hepatocytes: A Trend Analysis. Poster Presented at 20th North American ISSX Meeting, Orlando FL, USA, 18-22 October 2015.

65. Jeong, S.; Nguyen, P.D.; Desta, Z. Comprehensive in vitro analysis of voriconazole inhibition of eight cytochrome P450 (CYP) enzymes: Major effect on CYPs 2B6, 2C9, 2C19, and 3A. Antimicrob. Agents Chemother. 2009, 53, 541-551. [CrossRef] [PubMed]

66. Foti, R.S.; Wahlstrom, J.L. CYP2C19 Inhibition: The Impact of Substrate Probe Selection on in Vitro Inhibition Profiles. Drug Metab. Dispos. 2008, 36, 523-528. [CrossRef]

67. Soars, M.G.; Petullo, D.M.; Eckstein, J.A.; Kasper, S.C.; Wrighton, S.A. An assessment of UDP-glucuronosyltransferase induction using primary human hepatocytes. Drug Metab. Dispos. 2004, 32, 140-148. [CrossRef] [PubMed]

68. Les Laboratoires Servier. Servier Medical At. Available online: https://smart.servier.com/ (accessed on 27 November 2020).

69. ChemAxon Bupropion. Available online: https://chemicalize.com/app/calculation/bupropion (accessed on 27 November 2020).

70. Takayanagi, T.; Itoh, D.; Mizugushi, H. Analysis of Acid Dissociation Equilibrium of Bupropion by Capillary Zone Electrophoresis after the Heat-Degradation. Chromatography 2016, 37, 105-109. [CrossRef]

71. Muralidhar, P.; Bhargav, E.; Srinath, B. Formulation and optimization of bupropion $\mathrm{HCl}$ in microspongesby $2^{3}$ factorial design. Int. J. Pharm. Sci. Res. 2017, 8, 1134-1144. [CrossRef]

72. Berezhkovskiy, L.M. Volume of distribution at steady state for a linear pharmacokinetic system with peripheral elimination. J. Pharm. Sci. 2004, 93, 1628-1640. [CrossRef]

73. Open Systems Pharmacology Suite Community. Open Systems Pharmacology Suite Manual, Version 7.0.0. 2017. Available online: http:/ / www.open-systems-pharmacology.org/ (accessed on 31 December 2020).

74. Xu, C.; Ogburn, E.T.; Guo, Y.; Desta, Z. Effects of the CYP2B6*6 allele on catalytic properties and inhibition of CYP2B6 in vitro: Implication for the mechanism of reduced efavirenz metabolism and other CYP2B6 substrates in vivo. Drug Metab. Dispos. 2012, 40, 717-725. [CrossRef] [PubMed]

75. Wang, P.F.; Neiner, A.; Kharasch, E.D. Stereoselective Bupropion Hydroxylation by Cytochrome P450 CYP2B6 and Cytochrome P450 Oxidoreductase Genetic Variants. Drug Metab. Dispos. 2020, 48, 438-445. [CrossRef]

76. Wang, X.; Abdelrahman, D.R.; Zharikova, O.L.; Patrikeeva, S.L.; Hankins, G.D.V.; Ahmed, M.S.; Nanovskaya, T.N. Bupropion metabolism by human placenta. Biochem. Pharmacol. 2010, 79, 1684-1690. [CrossRef] [PubMed]

77. Chen, Y.; Liu, H.F.; Liu, L.; Nguyen, K.; Jones, E.B.; Fretland, A.J. The in vitro metabolism of bupropion revisited: Concentration dependent involvement of cytochrome P450 2C19. Xenobiotica 2010, 40, 536-546. [CrossRef] [PubMed]

78. Arias, H.R.; Gumilar, F.; Rosenberg, A.; Targowska-Duda, K.M.; Feuerbach, D.; Jozwiak, K.; Moaddel, R.; Wainer, I.W.; Bouzat, C. Interaction of Bupropion with Muscle-Type Nicotinic Acetylcholine Receptors in Different Conformational States. Biochemistry 2009, 48, 4506-4518. [CrossRef]

79. Simonsen, U.; Comerma-Steffensen, S.; Andersson, K.E. Modulation of Dopaminergic Pathways to Treat Erectile Dysfunction. Basic Clin. Pharmacol. Toxicol. 2016, 119, 63-74. [CrossRef]

80. Carroll, F.I.; Blough, B.E.; Abraham, P.; Mills, A.C.; Holleman, J.A.; Wolckenhauer, S.A.; Decker, A.M.; Landavazo, A.; McElroy, K.T.; Navarro, H.A.; et al. Synthesis and biological evaluation of bupropion analogues as potential pharmacotherapies for cocaine addiction. J. Med. Chem. 2009, 52, 6768-6781. [CrossRef] 
81. ChemAxon Hydroxybupropion. Available online: https://chemicalize.com/app/calculation/Hydroxybupropion (accessed on 27 November 2020).

82. ChemAxon Erythro- and Threohydrobupropion. Available online: https://chemicalize.com/app/calculation/CC(NC(C)(C)C)C(O)C1 $\% 3 \mathrm{DCC} \% 3 \mathrm{DCC}(\mathrm{Cl}) \% 3 \mathrm{DC} 1 \% 20$ I lp $\% 3 \mathrm{~A} 2 \% 3 \mathrm{~A} 1 \% 2 \mathrm{C} 8 \% 3 \mathrm{~A} 2 \% 2 \mathrm{C} 14 \% 3 \mathrm{~A} 3$ | (accessed on 27 November 2020).

83. PubChem Hydroxybupropion. Available online: https:/ / pubchem.ncbi.nlm.nih.gov/compound/446 (accessed on 27 November 2020).

84. Kawai, R.; Lemaire, M.; Steimer, J.L.; Bruelisauer, A.; Niederberger, W.; Rowland, M. Physiologically based pharmacokinetic study on a cyclosporin derivative, SDZ IMM 125. J. Pharmacokinet. Biopharm. 1994, 22, 327-365. [CrossRef] [PubMed]

85. Guest, E.J.; Aarons, L.; Houston, J.B.; Rostami-Hodjegan, A.; Galetin, A. Critique of the Two-Fold Measure of Prediction Success for Ratios: Application for the Assessment of Drug-Drug Interactions. Drug Metab. Dispos. 2011, 39, 170-173. [CrossRef] [PubMed]

86. Shimokawa, Y.; Yoda, N.; Kondo, S.; Yamamura, Y.; Takiguchi, Y.; Umehara, K. Inhibitory Potential of Twenty Five Antituberculosis Drugs on CYP Activities in Human Liver Microsomes. Biol. Pharm. Bull. 2015, 38, 1425-1429. [CrossRef] [PubMed]

87. Rajaonarison, J.F.; Placidi, M.; Lacarelle, B. Screening in Human Liver Interactions for Inhibitors. Drug Metab. Dispos. 1994, 20.

88. Xue, C.; Zhang, X.; Cai, W. Prediction of drug-drug interactions with bupropion and its metabolites as CYP2D6 inhibitors using a physiologically-based pharmacokinetic model. Pharmaceutics 2018, 10, 1. [CrossRef]

89. Connarn, J.N.; Zhang, X.; Babiskin, A.; Sun, D. Metabolism of Bupropion by Carbonyl Reductases in Liver and Intestine. Drug Metab. Dispos. 2015, 43, 1019-1027. [CrossRef]

90. Giri, P.; Naidu, S.; Patel, N.; Patel, H.; Srinivas, N.R. Evaluation of In Vitro Cytochrome P450 Inhibition and In Vitro Fate of Structurally Diverse N-Oxide Metabolites: Case Studies with Clozapine, Levofloxacin, Roflumilast, Voriconazole and Zopiclone. Eur. J. Drug Metab. Pharmacokinet. 2017, 42, 677-688. [CrossRef] [PubMed]

91. Sager, J.E.; Tripathy, S.; Price, L.S.L.; Nath, A.; Chang, J.; Stephenson-Famy, A.; Isoherranen, N. In vitro to in vivo extrapolation of the complex drug-drug interaction of bupropion and its metabolites with CYP2D6; simultaneous reversible inhibition and CYP2D6 downregulation. Biochem. Pharmacol. 2017, 123, 85-96. [CrossRef] 